\title{
Measuring Decent Work with Statistical Indicators
}

\author{
Working Paper No. 2 \\ Richard Anker, Igor Chernyshev, Philippe Egger, \\ Farhad Mehran and Joseph Ritter
}

Policy Integration Department Statistical Development and Analysis Group International Labour Office Geneva

October 2002

Working papers are preliminary documents circulated to stimulate discussion and obtain comments 



\section{Contents}

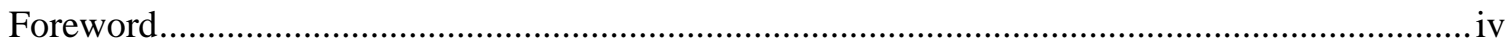

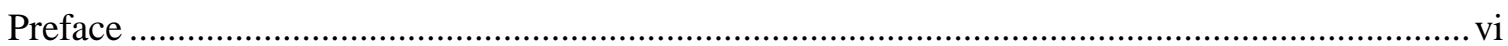

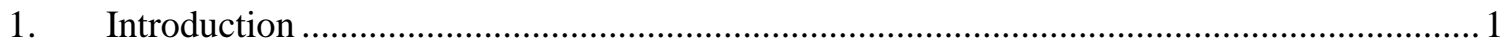

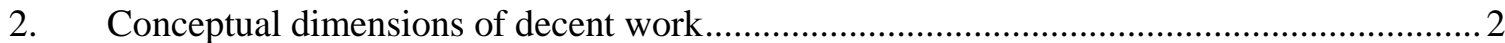

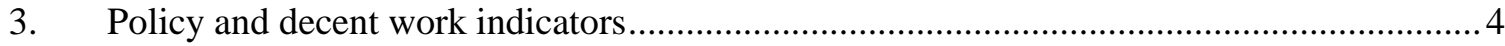

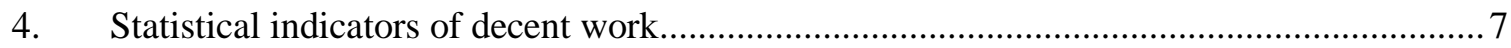

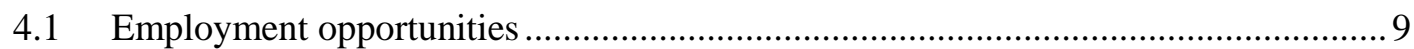

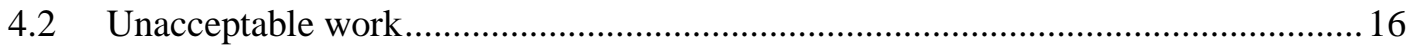

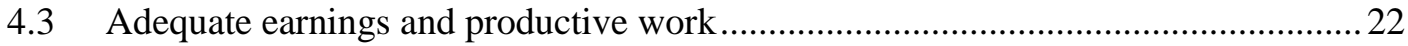

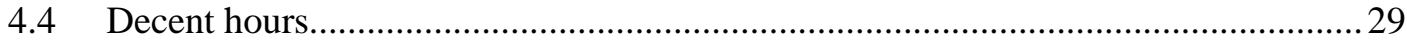

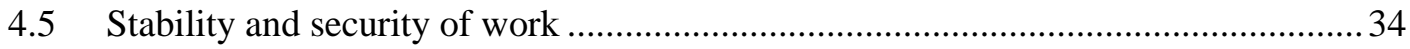

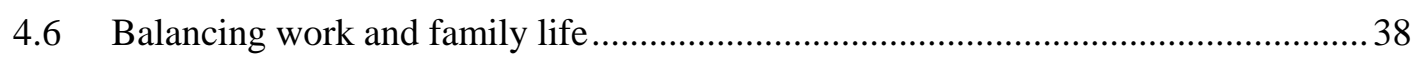

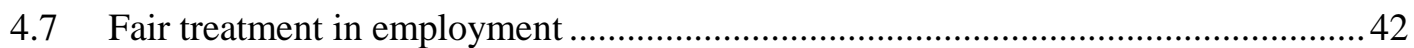

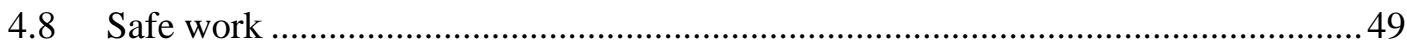

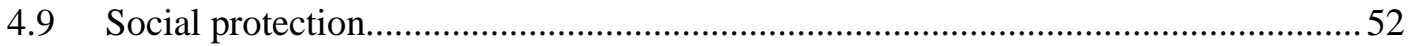

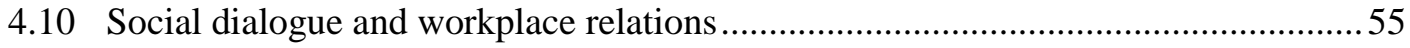

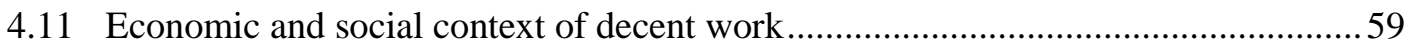

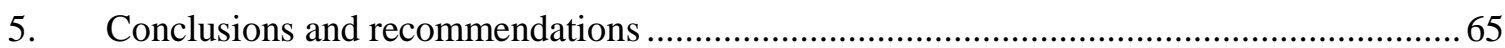

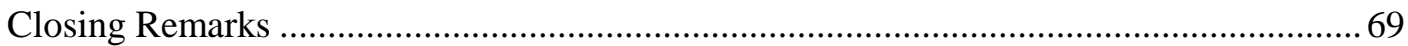




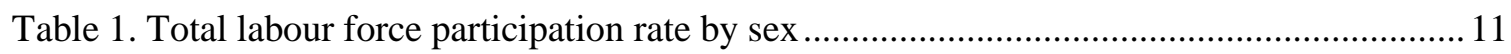

Table 2. Employment-population ratio and labour force participation rate................................ 11

Table 3. Unemployment rate and employee-specific unemployment rate (percentage).............. 13

Table 4. Youth unemployment rate and youth unemployment-population ratio........................ 14

Table 5. Share of wage and salary employment in non-agricultural employment .................... 15

Table 6. Percent of children not attending school and economic activity ............................... 19

Table 7. Child activity rate by employment status ............................................................ 21

Table 8. Percentage of workers with gross hourly earnings below half of median .....................26

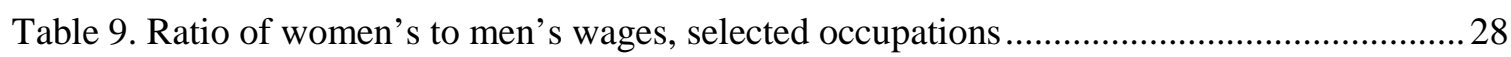

Table 10. Percentage of employed persons participating in job-related education or training during the previous year.............................................................................. 29

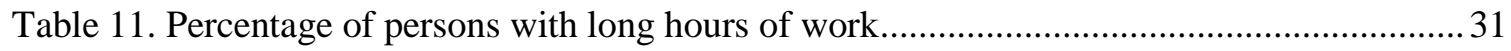

Table 12. Percentage of underemployed workers among the employed population ...................33

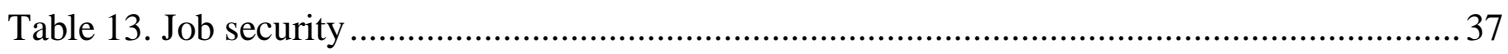

Table 14. Employment rate of women with children under 6 and related information ..............40

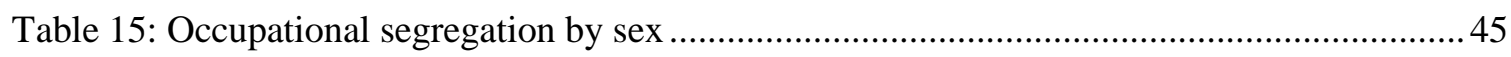

Table 16. Women in managerial and administrative occupations ....................................... 47

Table 17 Ratio of female to male unemployment rate.................................................... 48

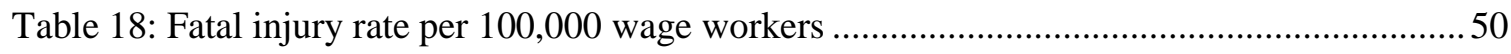

Table 19. Percentage of labour force protected by employment injury insurance .....................51

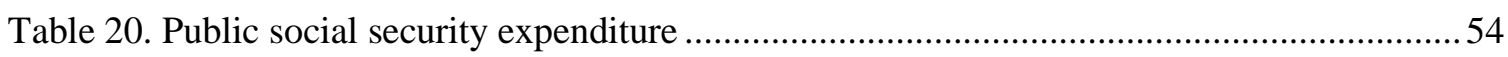

Table 21. Union density rate and collective bargaining coverage rate (percent of wage workers)56

Table 22. Days lost through industrial action per 1,000 wage employees (3-year averages) ........57

Table 23: Informal economy employment as percent of employment, rural and urban ..............65

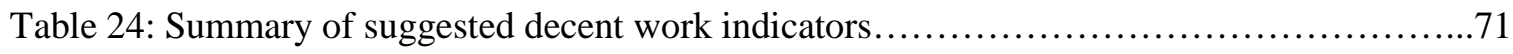


Figure 1. Distribution of employees by gross hourly earnings.................................................. 24

Figure 2. Occupational segregation by sex (ID) by level of disaggregation in occupational

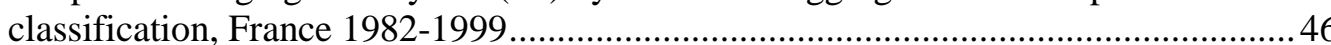




\section{Foreword}

This is the second paper to be issued in the Policy Integration Department's new series. The Department was created to promote and support a more integrated approach to the different dimensions of the decent work agenda, and this paper is intended to do just that.

The decent work agenda brings together the goals of rights at work, employment, social protection and social dialogue in a consolidated, gender-sensitive vision which guides economic and social policy choices across the board. Each unit of the ILO today determines its programme so as to contribute to one or more of these decent work goals.

Within this framework, policy integration is concerned with bringing together the different dimensions of the ILO's work so that they reinforce and complement each other. The aim is two fold. First, to increase the capacity of the ILO to respond to integrated economic and social problems. Examples include the social dimension of globalization, or the integration of decent work goals and instruments into strategies for poverty reduction. Second, to increase capacity to tackle many specific issues by treating them as part of a wider agenda. For instance, a combination of normative and economic policy interventions is likely to be more effective than the sum of both taken separately. Social dialogue is legitimized and reinforced when it helps to build a virtuous circle of economic development which creates jobs and generates resources for social protection.

This also illustrates what we mean by the expression policy integration: it refers to policies which take into account the interaction between economic and social goals, instruments and behaviour, and so involves the design of a consistent set of policies covering different domains.

This is in the first instance a policy agenda, but behind it lie important issues of analysis and measurement.

In his report to the 2001 International Labour Conference, the Director-General wrote: "In order to effectively promote the goal of decent work for all, the Office must be able to measure and monitor progress and deficits... At present our information systems provide only a partial, and sometimes only a rudimentary, picture of decent work deficits... If there is one place in the world where people can turn for quality information on decent work, it should be the ILO. We need to make a major investment in the design and implementation of our data and statistical base."

In order to make that investment, we need to have a clear view of where the priorities lie. Decent work is a broad concept, with many dimensions. Some of its dimensions are much more readily measured than others, and that is reflected in the availability of statistics on different topics. It is, on the whole, easier to measure employment than it is to measure freedom of association. But while inevitably one ends up measuring the measurable, the very nature of decent work as an integrated framework calls for an approach which attempts to address the difficult issues. If we cannot measure progress towards decent work, it is difficult to get beyond rhetoric and into the hard policy choices. This is a fundamental issue, a foundation for much else.

The contribution of this paper is to suggest a lean set of indicators of decent work, for which data exist in many countries now, and which can be used to set priorities for the 
future. It is not the last word on the subject; rather it aims to provoke discussion and feedback.

There are many efforts under way across the Office to expand our capacity to measure progress towards decent work. In addition to the core activities of the Bureau of Statistics, that includes a major programme of data collection on socio-economic security, there is a substantial programme of surveys on child labour; the major continuing effort on employment issues reflected in work on key indicators of the labour market; and a number of smaller projects. The present paper aims to build on and complement these existing efforts. It suggests statistical priorities for the Office, which would help bring our statistical work into closer alignment with our policy agenda around decent work. So in a very practical sense, this paper is a contribution to an integrated approach to the goal of decent work.

This paper was prepared by a team led by Richard Anker, as part of the work of the Statistical Development and Analysis Unit which he heads. It draws on consultations and expertise from across the Office.

September 2002

Gerry Rodgers

Director

Policy Integration Department 


\section{Preface}

In his first report to the International Labour Conference in 1999, ILO Director General Juan Somavia introduced a comprehensive concept of work and the workplace, which he called Decent Work. He described decent work as "opportunities for women and men to obtain decent and productive work in conditions of freedom, equity, security and human dignity". Decent Work has subsequently become the organising framework for ILO activities. This widely quoted passage, however, provides only a broad description of the basic elements of decent work.

There is no agreed set of statistical indicators to measure decent work. Indeed, some believe that decent work is a well meaning, nice sounding phrase that is not definable or measurable. This lacuna as regards decent work indicators greatly hampers ILO's own work, as well as the ability of its constituents to monitor and evaluate the situation in their countries. It means that it is not possible for constituents to know progress toward the achievement of decent work or the position of their country or with regard to other countries. It means that the ILO's ability to communicate with and advise constituents is reduced, as is its ability to communicate with the public. Nor is it possible to understand how decent work relates to poverty and other major development concerns, or how different dimensions of decent work interrelate. This need for a core set of statistical indicators to measure decent work was recognised by the Advisory Group on Statistics (AGS) in its recommendations to the Director General in 2001.

ILO's failure to effectively communicate the importance of decent work is evident in the United Nations' Millennium Development Goals. Despite our position that decent work is a pivotal aspect for effective development and poverty reduction, only two out of the 48 indicators developed to monitor these Goals directly relate to work. And both of these indicators measure only the presence or absence of work and not the decency of work itself.

It is clear that a major effort will be required if a comprehensive set of decent work indicators is to be identified, developed and measured. This effort will need to be focused and involve the entire ILO, including the regions, and require the cooperation and collaboration of constituents. National statistical services will also need to be involved over the long run. The Office will need to build on and coordinate the major on-going statistical activities already underway such as in STAT, IFP/SES, KILM, and IPEC at headquarters, and in the regions. A collaborative ILO effort must start with an agreed core set of decent work indicators. While countries, regions and technical programmes should be encouraged to augment the core indicators to address special issues, it is nevertheless important for everyone to work together to measure an agreed core set of decent work indicators. Otherwise, efforts will become splintered and uncoordinated. This would end with unsatisfactory results in my opinion-in part because the job ahead is so challenging and available resources are limited, in part because it would limit our ability to look at decent work in a comprehensive way, and in part because it would limit international comparisons, as well as world and regional estimates.

This paper has been prepared by the Statistical Development and Analysis Unit of the Policy Integration Department (INTEGRATION/SDA) in light of the clear need for an agreed set of decent work indicators. In doing this, we did not shy away from pointing out conceptual and measurement difficulties, or serious gaps in the coverage of the indicators. We felt it important to be realistic. Our recommendations consider feasibility (especially in terms of data availability for a range of developing, transition and developed countries), clear relevance to one or more aspect of decent work, and the possibility of achieving 
acceptable international comparability. It does little good to suggest indicators that cannot be compiled for a range of countries at varying development levels, are not conceptually relevant for decent work, and/or cannot be measured with reasonable accuracy and crosscountry comparability. Indeed, we felt that pointing out difficulties and rejecting possible indicators was as important as identifying and suggesting indicators. At the same time, it is important that there is continual development of indicators so that what can be measured at the present time for a substantial number of countries is a first step in a process of measuring decent work.

This paper was prepared in a truly team effort by Richard Anker, Igor Chernyshev, Philippe Egger, Farhad Mehran and Joe Ritter (names are in alphabetical order). Statistical assistance for computing some of the suggested indicators has been provided by David Bescond. At each stage in preparation of this paper, we sat around a table to discuss the issues and preliminary conclusions of one member of the team. Discussions were often pointed and tough, but they were always conducted in a professional and collegial manner, with a satisfactory conclusion the overriding goal of everyone. These internal discussions were preceded by discussions with relevant ILO technical units. We also benefited from the comments and suggestions of colleagues in the Policy Integration Department: Gerry Rodgers, Anne Trebilcock, Sylvester Young, Eivind Hoffmann, Adriana Mata-Greenwood and Rolph van der Hoeven. And from comments of other colleagues such as Jacqueline Ancel-Lenners, Lucio Baccaro, Abbas Bazargan, Roger Böhning, Dharam Ghai, Wouter van Ginneken, Frank Hagemann, Jean-Claude Javillier, David Kucera, Oliver Liang, Amy Ritualo, Ellen Rosskam, Frans Roselaers, Bill Salter, Carmen Sottas, Lee Swepston, Hamid Tabatabai and Monique Zarka-Martres among others. This means that considerable discussion, dialogue and thought have already gone into this project. At the same time, we are well aware of this paper's limitations, and so we do not see it as a final document or blueprint for the Office. Rather, we hope it will provide the basis for constructive dialogue and discussion.

The central premise of this paper is that it is important for the ILO to settle on a basic core set of decent work indicators and a plan of action for statistical activities. The Office should also seriously consider developing a complementary set of indicators to measure supporting national and international legal frameworks and conventions for the eleven major aspects of decent work identified in this paper. Inaction or unnecessary procrastination would be a bad outcome for the ILO in our opinion. INTEGRATION/SDA looks forward to reactions and constructive criticisms that move the ILO toward the goal of identifying a core set of ILO decent work indicators and developing the capacity to measure them.

September 2002

Richard Anker

Statistical Development and Analysis Unit Policy Integration Department 



\section{Introduction}

How decent is your work? Every person at work or looking for work, whatever his or her country, occupation or skill level, has a notion of what decency at work stands for. Since work is a major part of life in terms of total time, social integration and individual self-esteem, decent work is clearly a fundamental dimension of the quality of life. Productive work is also the main source of income for the vast majority of people and the driving force for sustainable development.

The promotion of decent work for all women and men everywhere is the central objective of the International Labour Organisation (ILO), which describes decent work as "opportunities for women and men to obtain decent and productive work in

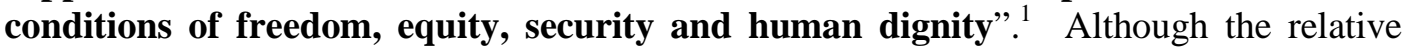
importance of specific aspects of decent work varies from country to country and from person to person, the concept and the basic elements of decent work are universal. It is also the belief of the ILO and many others that decent work is an important contributor to sustainable development, in addition to being an important objective in its own right.

The present paper focuses on the measurement of decent work. It is a first step in a major effort at the ILO to: (i) measure with statistical indicators decent work and progress toward decent work around the world, and (ii) empirically document relationships between different aspects of decent work, and between decent work, poverty and economic performance. Its objectives are: to translate the concept of decent work into easily understood characteristics of work, to identify statistical indicators of these characteristics that can be measured right now with an acceptable degree of consistency, accuracy and cross-country comparability, and to identify further statistical activities and indicators to improve the measurement of decent work in the future. The ultimate objective of this paper is to provide the basis for arriving at an agreed minimal core set of ILO decent work indicators.

Section 2 describes in more detail the different dimensions of decent work included in the succinct description of decent work quoted above, as well as implications for measuring decent work with statistical indicators. Section 3 discusses important policy issues which can be addressed with decent work statistical indicators. Section 4 is the heart of this paper. It begins by describing the general approach to measuring decent work with statistical indicators used in this paper, and briefly introducing 11 broad aspects of decent work. Approximately four page discussions of statistical indicators for each of these aspects of decent work follow. Subsections for each of these 11 broad aspects of decent work include: background on why each aspect is important for measuring decent work, suggested indicators for immediate measurement, and discussion that includes illustrative data, likely measurement difficulties, and possible developmental work for improving measurement in the future. Section 5 draws conclusions and makes recommendations about what needs to be done to measure the statistical indicators of decent work identified in section 4 for a sizable number of countries in all regions of the world.

It should be emphasised at the onset of this paper that it does not provide a final set of ILO decent work indicators, even though substantial thought and internal ILO discussion have gone into identification of the suggested indicators. Rather, it suggests a core set of

${ }^{1}$ ILO, Decent Work: Report of the Director General, International Labour Conference, $87^{\text {th }}$ Session. 
ILO decent work indicators and should be seen as a serious first step in a process. Arriving at a final and agreed core set of ILO decent work indicators will require taking into consideration reactions, and further inputs and constructive comments from units throughout the Organisation and constituents. In any case, it is important to note that even an agreed ILO core set of decent work indicators will not be final or complete in at least two very important ways. First, improved measurement over time will allow for a broader core set of indicators in the future. And second, countries, regions and technical programmes will need and want additional indicators that are measurable and important for them. At the same time, it is essential that a core set of ILO decent work indicators be agreed on relatively soon, though the process of actually compiling data for the indicators will undoubtedly result in modifications to the agreed list in the future. In this way, the considerable ongoing work on statistical activities in the ILO, including major efforts such as in STAT, IFP/SES and KILM at headquarters and Latin America in the regions, will be much more likely to result in comprehensive measurement of decent work. ${ }^{2}$

\section{Conceptual dimensions of decent work}

The definition of decent work as "opportunities for women and men to obtain decent and productive work, in conditions of freedom, equity, security and human dignity" explicitly includes six dimensions.

1. Opportunities for work refers to the need for all persons (men and women) who want work to be able to find work, since decent work is not possible without work itself. The underlying concept of work is a broad one, encompassing all forms of economic activity, including self-employment, economic unpaid family work and wage employment in both the informal and formal sectors.

2. Work in conditions of freedom underscores the fact that work should be freely chosen and not forced on individuals and that certain forms of work are not acceptable in the 21st century. It means that bonded labour and slave labour as well as unacceptable forms of child labour should be eliminated as agreed by governments in international declarations and labour standards. It also means that workers are free to join workers organisations.

3. Productive work is essential for workers to have acceptable livelihoods for themselves and their families, as well as to ensure sustainable development and competitiveness of enterprises and countries.

4. Equity in work represents workers' need to have fair and equitable treatment and opportunity in work. It encompasses absence of discrimination at work and in access to work and ability to balance work with family life.

5. Security at work is mindful of the need to help safeguard health, pensions and livelihoods, and to provide adequate financial and other protection in the event of health and other contingencies. It also recognises workers' need to limit insecurity associated with the possible loss of work and livelihood.

6. Dignity at work requires that workers be treated with respect at work, and be able to voice concerns and participate in decision-making about working conditions. An essential ingredient is workers' freedom to represent their interests collectively.

2 See Anker, R. ILO Multi-country databases, ILO, Geneva, 2001, for a description of 46 ILO multi-country databases maintained by these and other ILO units. 
The first two dimensions of decent work noted above (opportunities for work and freedom of choice of employment) are concerned with the availability of work and the acceptable scope of work. The other four dimensions of decent work (productive work, equity, security and dignity) are concerned with the extent to which the work is decent, which is similar in many ways to what is deemed quality of employment in European publications.3 In addition to these six dimensions of decent work, the macro socioeconomic context is important, since this helps determine what constitutes decency in societies as well as the extent to which the achievement of decent work enhances national economic, social and labour market performance.

Before describing specific statistical indicators in section 4 , it is important to highlight important implications of the decent work concept for the identification of statistical indicators.

- The six dimensions of decent work included in the short description of decent work are relevant for everyone - for men and women, persons in high and low income countries, and work in the modern and traditional sectors.

- Some aspects of decent work are absolute in nature in the sense that the same standard applies to everyone in every country (e.g., fundamental rights at work). Other aspects of decent work are relative in that each country and society evolves its own norms of decency. For example, while the level of pay and working conditions considered to be decent differs across countries, the principle that as many persons as possible should have decent pay and working conditions is a universally accepted concept.

- Decent work is especially concerned about the poorest and most vulnerable. The word "decent" connotes this, referring to the need for workers to have "acceptable" or "adequate" work and working conditions. This, in turn implies that decent work indicators should often be concerned with distributions and measuring the situation of the least well off rather than averages.

- Decent work is concerned with the actual situation people face. For this reason, decent work indicators generally should measure actual outcomes and conditions. When considering the legal situation in a country or international standards, indicators should, whenever possible, measure effectiveness and coverage.

- Because the decent work concept is concerned with improving the situation of people, it is important to measure changes over time in order to ascertain progress (or the lack of progress) and sustainability toward achieving decent work. This implies that changes in country situations could be ascertained while ensuring a reasonable degree of international comparability.

- Since one of the hallmarks of decent work is its comprehensive nature, it is important that decent work indicators reflect this comprehensive nature. Besides being necessary to describe decent work in its entirety, it is also important in order to observe the extent to which different aspects of decent work bundle together for workers, enterprises and countries, as well as how combinations of different decent work aspects interrelate to poverty and economic growth.

${ }^{3}$ See for example, Damien Merlié and Pascal Paoli, Third European Survey on Working Conditions 2000, Office for Official Publications of the European Communities, Luxembourg. And Employment in Europe 2001: Recent Trends and Prospects (chapter 4), Office for Official Publications of the European Communities, Luxembourg. 
- Data availability and relative importance of different decent work aspects vary greatly across countries and regions. Therefore, any internationally acceptable core set of ILO decent work indicators will need to be a minimal set. Specific countries, regions and technical programmes will frequently want to identify and measure additional decent work indicators.

\section{Policy and decent work indicators}

The traditional focus of data collection and statistics in the labour sphere has been on employment and unemployment, with the latter grabbing most of the headlines. This is clearly insufficient. The volume of employment generated by an economy at any point in time does not tell us much about the life or person-enabling characteristics of employment.

A useful parallel can be drawn with economic growth and human welfare. A sustained increase in national aggregate income per capita is the most common measure of economic development and a necessary dimension of higher levels of human welfare. However, as the pioneering work of UNDP on human development indicators and the Human Development Index have shown, an aggregate measure such as gross domestic product per person is only one dimension of development, and higher levels of aggregate income do not translate perfectly into higher levels of human welfare, such as longer life and better education, health and housing for instance. Even though these different measures of human welfare may be highly correlated with average income, it is important for policy purposes to know whether better education, housing, etc. are outcomes of faster growth, essential conditions for growth, or both. Nor do aggregate income measures tell much about how the additional income is distributed among the population, and whether all groups experience similar absolute or relative increases in their income.

Only by moving beyond averages and into the details of causal relationships is it possible to obtain an adequate understanding of the policy priorities required to obtain rapid development. Thus, there is the parallel between the current over-reliance in the labour area on unemployment and employment, and a relative neglect of other aspects of decent work. Following the analogy with the HDI, while unemployment and employment remain important just as per capita GDP remains important, more employment intensive patterns of economic growth should remain an essential objective, but not to the exclusion of adequate pay, acceptable levels of mental, physical and financial risk, social protection and respect for internationally recognized rights. This in turn implies that policy initiatives, effective advocacy, and policy-making for decent work require new indicators as well as expanded and new data sets.

Four areas on which additional comprehensive decent work indicators and data can shed new light for policy-making purposes in relation to decent work are briefly discussed below.

\section{Poverty reduction through decent work}

The United Nations Millennium Assembly adopted the ambitious target of reducing by half the number of persons living in extreme poverty by 2015 from its 1990 level. Current knowledge about poverty strongly suggests that economic growth is a necessary, but not a sufficient condition for sustained reduction in poverty. Rising labour productivity is indispensable if economic growth is to lead to less poverty. For any given rate of economic growth, different combinations of economic, employment and social policies will lead to faster or slower poverty alleviation. It is these combinations that are of particular interest to countries committed to poverty alleviation. Aggregate data on the share of the population living in extreme poverty do not reveal whether poverty results 
from insufficient employment, low rates of pay, inability to work due to an uncompensated injury at work, discrimination, lack of access to social protection, unavailability of a basic pension, or one of the many other aspects of labour markets observed the world over. Better measurement of decent work, and especially the extensiveness of social protection and low pay will provide useful insights into the many possible policy options to address poverty. Understanding decent work and its relationship to poverty is, therefore, a critical aspect of the struggle to reduce extreme poverty by half by 2015. Another consequence of not having an agreed set of ILO decent work indicators has been the serious underemphasis of decent work among the Millennium Development Goal indicators, as only two of their 48 indicators relate to work (youth unemployment rate and women's share of nonagricultural wage employment) and both of these measure the availability or absence of work and not its decency.

\section{Decent work, social dimensions of globalisation, and sustainable development}

It is possible to point to a number of countries that have decisively reduced poverty. It is more difficult to establish through quantitative analysis that decent work promotes high and sustained economic growth and social development. This point is central to discussions about the uneven distribution of social and economic benefits of globalisation between and within countries. The ILO view is that countries are in a better position to benefit from globalisation with an appropriate balance between economic and social development, and that this in turn leads to more decent work. New data on decent work and empirical analysis are necessary to substantiate these views. Similarly it can hardly be disputed that an appropriate balance between economic and social development is required as a basis for sustained economic growth. It is even possible to suggest the composition of the different elements with regard to employment, fundamental rights, social protection and social dialogue. Since the difficulty lies in suggesting where this appropriate balance lies for any given country and what are the options available to achieve and sustain it within a given set of constraints, empirical analysis is indispensable to aid policy making.

\section{Better jobs lead to better lives}

Better and more comprehensive measurement of decent work will allow for a more detailed assessment of the mechanisms by which economic growth translates into higher standards of human welfare, and how these in turn lay the ground for faster economic and social development. Work can be characterized in terms of multiple dimensions of decent work. Of particular interest are the combinations and the patterns that emerge among demographic and socio-economic groups. Some of these relationships are generally accepted. Poor health and unsafe working conditions increase absenteeism and reduce labour productivity. Employment insecurity and short tenure are related to accident rates, and poor working conditions are related to high job turnover. ${ }^{4}$ Higher rates of trade union membership are associated with higher labour productivity ${ }^{5}$, and greater participation in decision making at the workplace is associated with greater job satisfaction. ${ }^{6}$ Systematic

${ }^{4}$ Bohle, P., Quinlan, M. \& Mayhew, C. "The health and safety effects of job insecurity: An evaluation of the evidence", in The Economic and Labour Relations Review, Vol. 12, No. 1, June 2001.

${ }^{5}$ Freeman, R. and Medoff, J.L. What do unions do? Basic Books, New York, 1984.

${ }^{6}$ Hamermesh, D. The changing distribution of job satisfaction, NBER working paper No. 7332, Sep. 1999. 
gender differences have been observed on many dimensions. Comprehensive decent work data could usefully inform analysts, observers and policy-makers about many other relationships. This is not, however, simply a matter of pointing out causal relations. Policy is about making informed decisions with a reasonable assessment of likely results and their magnitude, including the inevitable ripples of indirect and unintended consequences. Better knowledge of these linkages would help provide a broader set of options for policy analysts and policy-makers.

\section{Counting decent jobs and decent establishments}

How many decent jobs are there in a country, how many decent workplaces are there in a country, and what percent of workers and workplaces in a country have decent jobs? These are important questions that can hardly be avoided. Answering these questions is often impossible, however, even when national estimates for an acceptable set of decent work indicators are available. The reason is that these questions can only be answered using micro individual job-level or establishment-level data, since it is necessary to determine whether each and every job or workplace is decent, and this requires information on all aspects of decent work for each individual or establishment (or a sample of them). It is also necessary to define what constitutes a decent work job and a decent workplace. This is not obvious if, as seems reasonable, a job or workplace could be considered decent if it has most but not all aspects of decent work. For example, is a job decent if it has high pay and has the right to organise but has limited protection; what if a job has high pay and rights as well as social protection but has excessively long hours? Since decision rules can be set, it is possible to answer the questions posed in the first sentence in this subsection when appropriate micro data are available. This has been done by the European Union. Using micro job data and three dimensions of job quality (job security, access to training and career development, and hourly wages), they estimate that 8, 17, 37, 38 percent of jobs in the European Union are what they describe as dead-end, low pay/ low productivity, reasonable, and good jobs respectively. ${ }^{7}$ Whenever possible, it is a good idea to answer the above questions using micro data and transparent decision rules.

\section{Country performance and a possible Decent Work Index}

Is decent work more prevalent in country A or country B? Has decent work improved in country A and/or country B? These are commonly expressed questions asked by the media, public, local leaders and national leaders. Such questions are typically answered using average national values for a series of indicators that have been aggregated into an index.

It would be possible to develop an ILO Decent Work Index (DWI), analogous to the HDI of UNDP. Such a flagship index could have considerable value to the ILO. It could help broaden the view of labour issues beyond the present focus on employment and unemployment. It would also be especially valuable for communication and advocacy purposes. On the other hand, there are major technical problems associated with composite indexes such as a DWI. These include the subjective judgement required to weight different indicators included in the DWI; how to handle situations when national data are missing for a specific indicator; the need to maintain simplicity and transparency in the construction of a DWI while covering all aspects of decent work. Failure to

\footnotetext{
${ }^{7}$ European Commission, Employment in Europe, European Communities, 2001.
} 
adequately address such problems could damage the credibility of the index and, possibly the ILO.

Several parts of the Office (e.g., Socio-Economic Security InFocus Programme, Institute of Labour Studies, and the Latin American regional office) have produced or are working on versions of a Decent Work Index. These efforts could be built on. Before the Office decides to develop and produce a flagship Decent Work Index, however, it will need to weigh the large potential value of a DWI against the major technical and practical difficulties involved in constructing and measuring such an index.

\section{Statistical indicators of decent work}

Statistical indicators of decent work are identified in this paper by looking through the eyes of people to identify general characteristics and specific indicators of decent work. We started with ten general characteristics of work that individuals from around the world would consider important elements of decent work. These ten aspects of decent work are complemented by an eleventh group of indicators that summarize key aspects of the economic and social context of decent work. This final group of indicators is intended to describe characteristics of the economy and population that form the context for determining levels, patterns, and sustainability of decent work. The 11 groups of indicators are:

1. Employment opportunities

2. Unacceptable work

3. Adequate earnings and productive work

4. Decent hours

5. Stability and security of work

6. Combining work and family life

7. Fair treatment in employment

8. Safe work environment

9. Social protection

10. Social dialogue and workplace relations

11. Economic and social context of decent work

Other approaches could have been taken. ${ }^{8}$ We could have organised the indicators around the internal programme structure and strategic objectives of the ILO. Our choice of looking through the eyes of people and using easily understood phrases and descriptions is based on our feeling that ILO decent work indicators should be easy to communicate to the person in the street. Note that the ten general characteristics of decent work do in fact

8 Other approaches which influenced discussions are found in Dharam Ghai in Decent work: Concepts, models and indicators, Discussion Paper, International Institute of Labour Studies, ILO, 2002; Guy Standing in Global Labour Flexibility: Seeking Distributive Justice, London, MacMillan, 1999; and European Communities (see footnote 3). 
represent the six dimensions of decent work included in the Director General's simple description of decent work noted above. Thus, employment opportunities helps represent opportunities for work, and unacceptable work helps represent work in conditions of freedom. Adequate earnings and productive work help represent productive work. Fair treatment at work, balancing work and family life, and social dialogue help represent equity and dignity at work. Safe work environment, social protection, and stability and security of work help represent security at work.

It is important to reiterate that the decent work indicators suggested in this paper represent a selected list which has been purposely kept as succinct as possible to enable the ILO, with its limited resources, to measure a full range of decent work concerns. Consequently, technical programmes and regions will often feel it necessary, and should be encouraged, to include additional indicators to take account of major policy issues and concerns for them. Individual countries will want to refine and augment the suggested indicators depending on data availability and their ability to undertake new data collection. In fact, countries will often want to exploit the special strengths of their own data, and so implement useful additional decent work indicators that are not suggested here.

There are a number of advantages to maintaining parsimony in an ILO core set of decent work indicators. It helps focus and prioritise ILO's statistical activities and so more effectively use its limited resources. Restricting the total number of indicators enables the ILO to devote more resources to development of new indicators and increasing crosscountry comparability of existing indicators. Third, a more manageable set of indicators will aid the ILO's efforts to encourage and assist countries in their own efforts to measure and monitor decent work.

Gender concerns are mainly addressed by observing differences between men and women for decent work indicators where gender is relevant. An underlying assumption is that all aspects of decent work are relevant for both men and women. This implies, then, that female-male differences provide the appropriate gender indicators in almost all instances.

Before beginning the discussion of specific indicators, it needs to be acknowledged that the suggested core set of decent work indicators is necessarily imperfect. Some may feel that it does not provide a full picture of decent work; others may think that it includes too many indicators. Some may be dissatisfied with the choice of indicators for particular aspects of decent work; others may be dissatisfied with the eleven aspects of decent work selected or with the placement of indicators within this framework. But we believe that it is an important and necessary start to have an agreed set of decent work indicators to work from.

As mentioned earlier, a primary aim of this paper is to catalyse discussion on decent work indicators. This discussion will need to recognize several realities. First, the resources of the ILO are limited. Second, judgement and compromise will be required to develop a core set of ILO decent work indicators. In particular, compromise will often be necessary between what is preferred conceptually and data availability, and between depth and breadth of decent work measurement.

The following subsections work their way through the eleven aspects of decent work listed above. In each case, suggested indicators include only those that are believed to have data available for a range of countries either now or in the relatively near future.

Other possible indicators and measurement approaches that require a longer planning horizon are outlined in the discussion. Small tables with data from developing countries, developed countries and transition countries have been assembled to provide readers with a 
rough idea of the values that can be expected for the suggested indicators as well as to illustrate possible conceptual, comparability, and methodological issues.

\subsection{Employment opportunities}

\section{Background}

The notion of decent work implies the existence of employment opportunities for all who are available for and seeking work. Therefore, an essential element of decent work is the extent to which a country's population is employed. Employment opportunities can be measured in a positive sense in terms of employment and labour force activity relative to the relevant population base. Employment opportunities can also be measured in a negative sense in terms of unemployment and underemployment and the lack of employment opportunities.

The ILO Employment Policy Convention, 1964 (No. 122) sets as a major national goal the pursuit of "an active policy designed to promote full, productive and freely chosen employment." In the accompanying Recommendation (No. 122), it is stipulated that employment policy "should be based on analytical studies of the present and future size and distribution of the labour force, employment, unemployment and underemployment."

\section{Indicators}

Six widely available indicators are suggested. Two measure employment opportunities directly (labour force participation and employment to population ratio), and three measure the lack of employment opportunities (unemployment, youth unemployment, underemployment). The share of wage employment in non-agricultural employment conveys considerable information about employment opportunities in a country, and other aspects of decent work are expressed in markedly different ways for employees than for self-employed workers; in addition, the female share of non-agricultural wage employment measures employment opportunities specifically for women and is a United Nations' Millennium goal indicator. Also, two additional indicators for further development are suggested in the discussion (employee-specific unemployment rate, and youth unemployment to total population ratio).

- Labour force participation rate

- Employment-population ratio

- Unemployment rate

- Youth unemployment rate

- Time-related underemployment rate (see entry under Decent Hours)

- Share of wage employment in non-agricultural employment

- Female share of non-agricultural wage employment 


\section{Discussion}

\section{Labour force participation rate}

The labour force participation rate measures the extent to which a country's workingage population is economically active. The labour force participation rate is an overall indicator of the level of labour market activity, and its breakdown by sex and age gives a profile of the distribution of the economically active population within a country, and for this reason could have been included with the economic and social context indicators. The labour force does not include persons, often women, engaged in non-economic activities, such as cooking at home or caring for own children - that is, activities that do not contribute to measured national income according to the system of national account statistics (SNA) definitions agreed by the international community. This conventional definition of the labour force, therefore, has implications on the interpretation of other related variables such as hours of work.

The labour force comprises the employed and the unemployed. The labour force participation rate-the size of the labour force relative to the size of the corresponding population-provides an aggregate measure of economic activity and is often used as the denominator for other indicators.

The ILO Bureau of Statistics maintains two databases on labour force and labour force participation rates. LABPROJ contains estimates and projections prepared by the ILO for the 178 countries and territories with at least 200,000 inhabitants in $1990 .{ }^{9}$ These estimates and projections are provided by sex and five year age group for 1950-2010 at ten year intervals plus 1995. The Bureau of Statistics intends to improve the comparability of these data as well as update the base year estimation to the year 2000. To analyse the structure and age profile of the male and female labour force and labour force participation rates, values could be provided for typical life cycle age groups, such as 15-24, 25-44, 4564 , and 65 and above.

The ILO Bureau of Statistics also produces comparable statistics on labour force participation rates for countries as part of its programme on ILO-Comparable annual employment and unemployment estimates. ${ }^{10}$ At present, the programme covers 33 countries; the results for 26 countries were last published in the ILO Bulletin of Labour Statistics 2001-2; and estimates for seven more countries are currently being prepared for publication in 2003. It would be possible to accelerate the expansion of this programme to cover some 50 or 60 countries by the end of 2002 by preparing estimates for additional selected countries on the basis of KILM data with estimates prepared in-house and sent to national statistical offices for review and approval.

The following table shows the latest data on the working age labour force participation rate in Indonesia and Norway from the ILO-Comparable programme. In both countries, the armed forces are included as part of the labour force. However, in Indonesia, the working-age population includes all persons aged 15 years and over, and in Norway all persons between 16 and 74 years of age. Other differences in definitions are considered minor.

${ }^{9}$ ILO Estimates and Projections of the Economically Active Population 1950-2010, Fourth edition. International Labour Office, Geneva, December 1996.

${ }^{10}$ For details about this programme, see Lawrence, S., "Comparable annual employment and unemployment estimates”, ILO Bulletin of Labour Statistics, ILO, Geneva, 2001-2002. 
Table 1. Total labour force participation rate by sex

\begin{tabular}{lccc}
\hline Country & \multicolumn{3}{c}{ Labour force participation rate (working age) } \\
\cline { 2 - 4 } & Both sexes & Male & Female \\
\hline Indonesia (1999) & 67.9 & 84.6 & 51.5 \\
Norway (2000) & 73.5 & 78.0 & 68.9
\end{tabular}

Source: Lawrence, Sophia, "ILO-Comparable annual employment and unemployment estimates," ILO Bulletin of Labour Statistics, International Labour Office (Geneva, 2001-2).

\section{Employment-population ratio}

The employment population ratio measures the proportion of the working age population that is employed. It provides information on the extent to which an economy generates work.

The following table compares the evolution of the employment-population ratio with that of the labour force participation rate in Indonesia and Norway for 1990 and 2000. It can be observed that the change in the employment-population ratio over this period in both countries has been greater than the corresponding change in the labour force participation rate.

Table 2. Employment-population ratio and labour force participation rate

\begin{tabular}{lccccccc}
\hline Country & \multicolumn{3}{c}{ Emp-pop. ratio (\%) } & \multicolumn{3}{c}{ LFPR (\%) } \\
\cline { 2 - 7 } & $\mathbf{1 9 9 0}$ & $\mathbf{2 0 0 0}$ & Diff & $\mathbf{1 9 9 0}$ & $\mathbf{2 0 0 0}$ & Diff \\
\hline Indonesia & 56.1 & $64.4^{1}$ & +8.3 & 63.3 & $67.9^{2}$ & +4.6 & +4.0
\end{tabular}

Notes: ${ }^{1}$ Refers to1997. ${ }^{2}$ Refers to1999. For working age population: 15 and above for Indonesia; $16-74$ for Norway.

Source: Lawrence, Sophia, "ILO-Comparable annual employment and unemployment estimates," ILO Bulletin of Labour Statistics, International Labour Office, Geneva, 2001-2.

Although not reported here, empirical evidence suggests that the employmentpopulation ratio has a higher correlation with economic development (measured by GDP per capita) than the labour force participation rate. The correlation between the employment-population ratio and economic development as measured by GDP per capita is stronger when the employment-population ratio is calculated for the prime-age population, 25-54 years old, and restricted to civilian employees. ${ }^{11}$

\section{Unemployment rate}

The unemployment concept was developed during the Great Depression of the 1930's to measure the number of persons with a total lack of work. The unemployment rate measures the number of unemployed persons as a percentage of the labour force. Persons of working-age are classified as unemployed if they were not employed or had not worked for even one hour in any economic activity (paid employment, self-employment, or unpaid

\footnotetext{
${ }^{11}$ Akyeampong, E.B., "Another measure of employment”, Perspectives, Statistics Canada, Othawa, Wileter, 1996, pp. 9-15.
} 
work for a family business or farm), were available for work, and had taken active steps to seek work during a specified recent period (generally the past week).

In most industrialised countries, the unemployment rate is regarded as an important indicator of labour market performance. In low-income countries, however, the significance and meaning of the unemployment rate is much more limited. In the absence of unemployment insurance or other public relief schemes, relatively few people can survive lengthy unemployment without family support. The majority of the workers must engage in some form of economic activity, however insignificant or inadequate. This is often in the informal economy and/or in self-employment. Also, owner cultivators often have work cycles that can cause measurement difficulties when a one week reference is used.

Several aspects of unemployment statistics cause non-comparability across countries, including for example, the data source (e.g. whether based on labour force survey questions, or on registration at employment offices), age group covered, how trainees and other particular categories of workers are counted, and the criteria for deciding what constitutes an active job search. Future work could improve the cross-country comparability of unemployment statistics, especially for developed countries where unemployment statistics are heavily relied on to measure economic and labour market conditions, by building on ILO's on-going work on comparable annual employment and unemployment statistics.

Since unemployment could be considered as essentially a paid employment phenomenon with virtually all unemployed persons seeking paid employment jobs, the risk of unemployment should be higher among persons in paid employment than those in selfemployment. Paid employment involves a contract between the employee and the employer, whether explicitly or implicitly. The contract is subject to breach by either party in a different way than when self-employed people go out of business. These arguments lead one to conclude that the unemployment rate has limited applicability in countries where self-employment is the dominant form of employment. These arguments also imply that when comparing unemployment rates among countries, standardization of concepts and definitions is not sufficient; the scope of application should also be considered. For this reason, it is proposed to develop an employee-specific unemployment rate indicator by expressing total unemployment as a percentage of the paid labour force, i.e., the sum of paid employment and unemployment. ${ }^{12}$

\section{- Employee-specific unemployment rate}

The following table shows results for Pakistan and France in 1999. On the basis of the conventional unemployment rate alone, it appears that the unemployment situation was half as serious in Pakistan (5.9 percent) as compared to France (11.8 percent). This result, which would be surprising to some, can be traced to the preponderance of paid employment in France (89.3 percent) and self-employment in Pakistan (63.6 percent). When the comparison is made using employees as the denominator as suggested just above, it can be observed that the rate in Pakistan (14.7 percent) is higher than in France (13.0 percent).

\footnotetext{
${ }^{12}$ Although it has rarely been used in practice, the notion of employee-specific unemployment rate is not new. It is recognized in the Resolution concerning statistics of the economically active population, employment, unemployment and underemployment, adopted by the Thirteenth International Conference of Labour Statisticians (Geneva 1982). As part of the recommended analytical concepts, the Resolution (para. 21(4)) specifies that "Unemployment rates, relevant to paid employment on the one hand and self-employment on the other, may be derived, whenever considered useful and feasible."
} 
Table 3. Unemployment rate and employee-specific unemployment rate (percentage)

\begin{tabular}{l}
\begin{tabular}{l} 
Country \\
\cline { 2 - 3 }
\end{tabular} \\
\cline { 2 - 3 }
\end{tabular}

The employee-specific unemployment rate $\left(r^{\prime}\right)$ is related to the general unemployment rate (r) by the following expression:

$$
r^{\prime}=r /[r+a(1-r)]
$$

where the parameter $a$ is the fraction of employees in total employment. In a country where all employed persons are employees, $a=1$ and $r^{\prime}=r$. In a country where only onethird of the employed population are employees, the employee-specific unemployment rate would be equal to $3 r /(1+2 r)$ where parameter $r$ is the general unemployment rate of that country. ${ }^{13}$ In this example, the employee-specific unemployment rate would be 2.3 times as great when the conventional unemployment rate is 20 percent and 2.7 times as great when the conventional unemployment rate is 5 percent. Further work is required to develop and test the employee-specific unemployment indicator. In particular, it is necessary to establish the extent to which there is low mobility between self-employment and paid employment and vice-versa. For example in a household survey at some point of the year, a self-employed person may not be seeking wage employment, while at another point in time the same person may be seeking such employment.

\section{Youth unemployment rate}

The population most at risk of unemployment is generally the educated youth entering the labour market for the first time. Youth unemployment rates are typically two or three times higher than the adult rates throughout the world. ${ }^{14}$ The goal to provide decent work for youth is one of the eight United Nations Millennium Goals and the youth unemployment rate is one of the 48 Millennium Goal indicators.

One reason for higher youth unemployment rates is that first-time jobseekers face greater difficulty due to lack of work experience and, often, limited access to job vacancy information. Since first-time job seekers are mostly young, it follows that youth unemployment rates are generally higher than the adult rates. Another reason is that

13 The formula may be particularly useful when data on the breakdown of employment into employees and others are not available for the same reference period as the unemployment rate by assuming that the share of employees remained constant.

${ }^{14}$ ILO, Youth and Work: Global Trends, International Labour Office, Geneva, 2001. 
younger workers have higher job turnover rates, and, at each re-entry they risk a new spell of unemployment. ${ }^{15}$

The problems of international comparability between developed and developing countries raised in the earlier section on the unemployment rate are also relevant for the youth unemployment rate. There is also an important international comparability issue in industrialised countries associated with how persons in vocational training are treated as regards labour force activity. In countries where vocational training generally takes place in school-type training institutions, the persons involved are treated in some countries as outside the labour force (such as France), thus decreasing the size of the labour force and increasing the youth unemployment rate. In other countries (such as Germany) where much of vocational training is carried out in enterprises and as part of the production process, the persons involved are treated as employed, thus increasing the labour force and decreasing the youth unemployment rate for the same number of unemployed. ${ }^{16}$ This distinction is particularly important in countries where training is used as an active labour market policy for the unemployed.

International comparability might be enhanced if the base for comparison might be the total youth population (including the economically inactive such as those in school and those enrolled in training institutions) instead of simply the labour force as in the conventional definition of youth unemployment. The resulting indicator could be called the youth unemployment-population ratio.

- Youth unemployment to total population ratio.

Table 4 compares the youth unemployment rate and the youth unemploymentpopulation ratio in three countries. It is interesting to note that the difference between the youth unemployment situation in France and Germany considerably narrows when using the unemployment-population ratio (7.5 percent and 7.3 percent, respectively) as compared to the unemployment rate (26.2 percent and 10 percent). Also, youth unemployment is highest in Trinidad \& Tobago whether measured on the basis of the conventional unemployment rate or the unemployment-population ratio. Thus, the relative values found on the basis of the unemployment-population ratio appear to be closer to expectation than those obtained from the employment rate.

Table 4. Youth unemployment rate and youth unemployment-population ratio

\begin{tabular}{lcccc}
\hline Country & $\begin{array}{c}\text { Unemployment rate } \\
(\%)\end{array}$ & $\begin{array}{c}\text { Unemployment- } \\
\text { population ratio (\%) }\end{array}$ & $\begin{array}{c}\text { Secondary gross enrolment } \\
\text { rate (\%) }\end{array}$ & $\begin{array}{c}\text { Tertiary gross } \\
\text { enrolment rate (\%) }\end{array}$ \\
\hline Trinidad \& Tobago $^{1}$ & 26.9 & 13.8 & 74 & 8 \\
France$^{2}$ & 26.2 & 7.5 & 111 & 51 \\
Germany2 $^{2}$ & 10.0 & 7.3 & 104 & 47
\end{tabular}

Notes: Youth refers to persons aged between 15 and 24 years. Gross enrolment rate refers to total enrolment divided by population of ages typical for students. ${ }^{1}$ Refers to1998. ${ }^{2}$ Refers to1999.

Source: "ILO Key Indicators of the Labour Market 2001-2002", ILO, Geneva, 2002, pp. 309-335 (KILM 9 Youth unemployment rate). UNESCO World Education Report 2000, tables 6 and 8.

15 O'Higgins, N., “The challenge of youth unemployment”, Employment Sector Employment and Training Papers 7, ILO, Geneva, 1997.

${ }^{16}$ Example borrowed from Ralf Hussmanns, ILO Bureau of Statistics. 
The example of Table 4 suggests that school enrolment rates have a much greater effect on the youth unemployment-population ratio than on the youth unemployment rate. Arithmetically, if individuals who would otherwise be unemployed become students (and do not seek employment), the unemployment to population ratio falls more than the unemployment rate because the denominator of the unemployment rate is reduced. Further work should be done to investigate this new suggested youth-unemployment to population ratio and to establish when it is a valuable complementary indicator to measure the youth unemployment situation.

\section{Share of wage employment in non-agricultural employment}

The share of wage and salary employment in non-agricultural employment is suggested as an indicator of employment opportunities, especially for developing countries, because it conveys considerable information about the nature of employment opportunities. With urbanization and rapid rural-urban migration, non-agricultural wage employment has not in recent years been able to keep pace with urban population growth This is largely because the non-agricultural economy has not immediately been able to absorb these workers in a way that takes advantage of the economies of scale and specialization that are the raison d'être of more complex forms of economic organisation. Instead, many urban workers unsuccessful in finding suitable wage employment can support themselves and their families only through self-employment in the unprotected informal economy. The statistical result is that the share of wage employment falls for all workers.

Wage and salary employment in the "formal" sector tends to have higher and more regular earnings, better benefits, and wider social protection than self-employment. This is the main reason that women's share of non-agricultural wage and salary employment was chosen as an indicator for the UN Millennium Goal of promoting gender equality.

In Table 5, Brazil and the Republic of Korea, report the smallest shares of wage employment 59 and 69 percent, in contrast with Canada's 85 percent. Transition economies, such as the Czech Republic, are an interesting contrast. These countries, because of their socialist past, have relatively low shares of self-employment, given their income levels. Self-employment shares in the transition economies are growing, however, by 1.4 percentage points in the Czech Republic between 1996 and 2000.

Table 5. Share of wage and salary employment in non-agricultural employment

\begin{tabular}{lcc}
\hline Country & $\begin{array}{c}\text { Share of wage employment in non- } \\
\text { agricultural employment }\end{array}$ & $\begin{array}{c}\text { Share of women in non-agricultural wage } \\
\text { employment }\end{array}$ \\
\hline Brazil (1999) a & 59.4 & 37.5 \\
Korea, Rep. of (2000) b & 69.1 & 39.9 \\
Czech Republic (2000) & 86.3 & 46.5 \\
Canada (2000) b & 85.1 & 48.2
\end{tabular}

Notes: a Data refer to individuals whose main work does not take place on a "farm, ranch, etc." b Shares of civilian employment.

Sources: LABORSTA database; Instituto Brasileiro de Geografia e Estatística (IBGE).

A number of aspects of decent work are expressed in markedly different ways for employees than for self-employed workers. In some cases the differences are simply part of what it means to be self-employed - the right to bargain collectively with one's employer is not meaningful for own-account workers, for example. In other areas, the contrast between employees and the self-employed is a matter of nuances of interpretation. 
As noted elsewhere, for example, most of the flow into unemployment comes from wage employment, so unemployment rates tend to be lower where wage employment is relatively rare. Another example is the interpretation of long hours of work. Because the self-employed are more able and likely to intermingle personal tasks with work, a long reported hours of work per week, say 60, carries a somewhat different implication. Wherever relevant, it is recommended that indicators be compiled separately by status in employment.

Four general observations that bear on these issues are worth mentioning. First, an obvious, but easily neglected caveat: Indicators that refer only to employees may refer to widely different shares of total employment in different countries. A second observation is a conceptual issue. There is no conflict of interest between employer and employee for the self-employed. Therefore, certain observations create different presumptions for the selfemployed than they would for employees. For example, among the self-employed, the failure to use appropriate safety equipment is almost certainly the result of lack of knowledge or affordability. Among employees, it may also signal the employer's willingness to tolerate - at the expense of employees - a higher injury rate. Third, selfemployment is higher in the informal economy than in the formal sector, so many of the distinctions between employees and the self-employed may reflect differences between formal and informal economy employment. Fourth, the distinction between paid employment and self-employment is not always clear. The status in employment of workers who perform subcontracted work depends on the control the contractor (or employer) has over, for example, how the work is performed, where the work is performed, when the work is performed, and how materials are purchased. Subcontracting has been important for some time now in developing countries with extensive family and home-based subcontracting production systems. It is becoming increasingly important in developed countries where so-called independent contractors are increasingly common. This is an area requiring further work.

\subsection{Unacceptable work}

\section{Background}

Decent work must be work that is acceptable to society. It is therefore necessary to know the incidence of unacceptable work, both to ensure that such work is excluded from indicators of employment opportunities as well as to measure progress towards its elimination. The 1998 ILO Declaration on Fundamental Principles and Rights at Work, which has won broad endorsement across the world community, identifies two forms of unacceptable work: forced labour and child labour (especially hazardous and other worst forms of child labour). 


\section{Indicators}

Two child labour indicators, that should proxy for unacceptable work by children, are suggested. Indicators for forced labour and additional indicators for child labour (e.g. children in hazardous and other worst forms) are left for future development because of the need to resolve major conceptual and measurement difficulties.

- Children not in school by employment status (percent by age)

- Children in wage employment or self-employment activity rate (percent by age)

Additional indicators may be possible in the future, since ILO has large on-going data collection efforts on child labour (Statistical and Information Programme on Child Labour, SIMPOC) and on forced labour (Programme on Fundamental Principles and Rights at Work). ILO also has considerable information on forced labour and child labour through its technical cooperation programmes and its supervisory system.

\section{Discussion}

\section{Child Labour}

Child labour can be detrimental to children in several ways. First, it can harm them physically and/or mentally. Second, work at an early age can crowd out schooling and consequently inhibit accumulation of important skills and capacities - this is one of the surest ways to greatly reduce employment options and choices in adulthood, and perpetuate poverty. The ILO Minimum Age Convention, 1973 (No. 138) and the Worst Forms of Child Labour Convention, 1999 (No.182) set the international standard on child labour. These two Conventions are designed to be dynamic and allow certain flexibility to accommodate differences among countries in setting their own national labour standards. Convention No. 138 generally defines the minimum working age at 15 years. ${ }^{17}$ The Worst Forms of Child Labour Convention calls for "as a matter of urgency" the elimination and prohibition of hazardous work which endangers health, safety and morals, as well as other worst forms of child labour, including slavery, debt bondage, prostitution, pornography, armed conflict, and trafficking. Furthermore, as stated in the recent ILO Global Report on child labour under the Follow-up to the ILO Declaration on the Fundamental Principles and Rights at Work, "the goal of decent work for all women and men cannot be achieved unless child labour is abolished". ${ }^{18}$

According to international standards, not all work that is carried out by children is deemed as unacceptable and so slated for abolition. When work is performed by young

${ }^{17}$ ILO Convention No. 138 obligates countries to fix the minimum age for employment or work at an age that is not less than 15 years and not less than the age of compulsory school. For purposes of flexibility, developing countries may set the minimum age at 14; however if this is the case, the minimum age should be progressively raised over time to meet the fullest physical and mental development of children. Furthermore, Convention No. 138 allows for children as of the age of 12 or 13 to perform "light work" which is "a) not likely to be harmful to their health or development; and b) not such as to prejudice their attendance at school, their participation of vocational orientation or training.....or their capacity to benefit from the instruction received." A minimum age of 18 is specified in Convention No. 182 for hazardous and other worst forms of work.

18 A future without child labour. Global Report under the follow-up to the ILO Declaration on Fundamental Principles and Rights at Work, International Labour Conference, $90^{\text {th }}$ session, 2002, page 117. 
persons below the minimum age for employment that is considered appropriate for their age and maturity level and does not interfere with their school attendance or capacity to learn, it can be acceptable and may even be beneficial to children. This type of work may teach young persons about responsibility and life skills or a particular trade, and can contribute to their own or their family's financial well-being. This means that it is necessary to measure unacceptable work by children to arrive at appropriate decent work child labour indicators. The two suggested indicators should be good proxies for unacceptable work by children.

\section{Children not in school}

The percentage of children not attending school is a good proxy measure for unacceptable child labour, as well as being a useful indicator and goal in its own right for child welfare. Indeed, universal school enrolment could be seen as a goal against which the elimination of unacceptable child labour can be measured. Despite the fact that the common assumption that school enrolment and child labour are mutually exclusive does not always hold true ${ }^{19}$, there is a strong correlation between school non-enrolment and economic activity of children. ${ }^{20}$

SIMPOC data on non-attendance in school and economic activity are provided for three countries in Table 6. Non-attendance rates range from around 10 to 34 percent for both 5-9 and 10-14 year old children in these countries. A relatively small percentage of children are both not in school and economically active. This ranges from 0 to 2 percent for children 5-9, and from 1 to 6 percent for children 10-14.

Data on school enrolment are available over time for many countries. It should be noted, however, that school enrolment is not the same as school attendance (as children may enrol in school but not attend school). Nor does school attendance necessarily imply satisfactory school performance or learning (as children may attend school irregularly, they may not spend sufficient time studying, they may repeat grades, school quality may be poor, or the school day or year may so short that effective learning may not be possible). In addition, enrolment rate data drawn from school records sometimes suffer from a disjoint between age and enrolment in specific grades due to late entry into school and/or grade repetition. Despite these various problems with school enrolment data, they nonethe-less provide useful proxy information for unacceptable child labour.

19 According to ILO/IPEC (2002) Every child counts: New global estimates of child labour, approximately half of children 5-9 and 10-14 who are in school are economically active; and approximately one-fifth of children 5-9 and one-half of children 10-14 who are not in school are economically active.

${ }^{20}$ Based on data for 14 developing countries from Africa, Asia, and Latin America compiled by ILO/IPEC, it is found that the primary school non-enrolment rate and the economic activity rate of children 10-14 are strongly related. The estimated slope is .64 for boys and .77 for girls, with approximately 50 percent of the variation in the primary school non-enrolment rate "explained" by the economic activity rate for 10-14 year olds. A similar positive relationship is found for some 25 African countries based on unpublished UNICEF data from their multi-purpose indicators cluster survey (MICS). 
Table 6. Percent of children not attending school and economic activity

\begin{tabular}{|c|c|c|c|c|}
\hline \multirow[t]{2}{*}{ Country/Schooling and economic activity } & \multicolumn{2}{|c|}{ Males } & \multicolumn{2}{|c|}{ Females } \\
\hline & $\begin{array}{c}\text { Age } \\
5-9\end{array}$ & $\begin{array}{c}\text { Age } \\
10-14\end{array}$ & $\begin{array}{c}\text { Age } \\
5-9\end{array}$ & $\begin{array}{c}\text { Age } \\
10-14\end{array}$ \\
\hline \multicolumn{5}{|l|}{ Kenya } \\
\hline Not in school & 34.4 & 24.9 & 32.7 & 26.5 \\
\hline Not in school and economically active & 2.2 & 3.8 & 1.9 & 3.7 \\
\hline $\begin{array}{l}\text { (Percent of those who are not in school who are } \\
\text { economically active) }\end{array}$ & (6.3) & $(15.2)$ & $(5.9)$ & $(13.9)$ \\
\hline \multicolumn{5}{|l|}{ Namibia a } \\
\hline Not in school & 10.1 & 8.9 & 9.4 & 5.5 \\
\hline Not in school and economically active & 1.5 & 2.7 & 0.9 & 1.2 \\
\hline $\begin{array}{l}\text { (Percent of those who are not in school who are } \\
\text { economically active) }\end{array}$ & $(14.4)$ & $(30.5)$ & $(9.7)$ & $(21.2)$ \\
\hline \multicolumn{5}{|l|}{ Turkey a } \\
\hline Not in school & 10.3 & 8.2 & 12.2 & 16.7 \\
\hline Not in school and economically active & $\mathrm{Ob}^{\mathrm{b}}$ & 5.6 & $0.2^{b}$ & 4.2 \\
\hline $\begin{array}{l}\text { (Percent of those who are not in school who are } \\
\text { economically active) }\end{array}$ & $\left(0^{b}\right)$ & $(67.9)$ & $\left(1.3^{b}\right)$ & $(25.5)$ \\
\hline
\end{tabular}

Notes: Data for 1999. a Ages 6-9. ${ }^{\mathrm{b}}$ Sample size less than 25.

Source: ILO SIMPOC, unpublished tabulations.

\section{Children in wage employment or self-employment}

Children working as employees or in self-employment is a second proxy indicator for unacceptable child labour, as it is relevant for the three overarching concerns about child labour. ${ }^{21}$ It often occurs under exploitative conditions and is often detrimental to health, safety and morals. These children often work full-time and under arduous conditions. This interferes with school attendance and performance which decreases lifetime employment options; it also interferes with a child's healthy development. This indicator has added advantages. It excludes unpaid family labour which is often legal at the national level, and is sometimes beneficial to children. It is relatively easy to measure in surveys and censuses in theory, since the required information can be obtained from a typical labour force question on status in employment. And it negatively affects employment opportunities and wage rates of adult workers (especially low paid adult workers). ${ }^{22}$

SIMPOC data for three countries are shown in Table 7. Relatively few economically active children are employees or self-employed in the two African countries according to

${ }^{21}$ See Anker, R. "The economics of child labour: A framework for measurement", International Labour Review, 2000/3, for discussion on the three main reasons for concern about child labour: protection of children, children's development, and economic and labour market impacts of child labour.

${ }^{22}$ The proportion of children involved in wage employment or self-employment is sensitive to the structure of the labour market, in particular the share of family labour in the economy. As can be seen with the data presented in table 7, rates are low in countries where wage labour is less prevalent (as in most African countries). 
these data. Approximately 95 percent of child workers 5-9 and between 80 and 90 percent of children workers 10-14 are unpaid family workers in these African countries (and only around 1.0 percent of children 10-14 and 0.5 percent of children 5-9 are in wage employment or self-employment). In contrast in Turkey, a much higher percentage of child workers 10-14 are wage employees or in self-employment (between approximately 25 and 50 percent) according to these data, although again few 6-9 year old children are in such work. The high rates for unpaid family work shown in Table 7 raise a very important issue about the extent to which some unpaid family work may be hazardous, and/or involve long hours that interfere with schooling. This deserves further investigation.

Two main types of data sources could be used to measure this child labour indicator. One could use household surveys that make a special effort to collect data on the economic activity of children, such as ILO's SIMPOC surveys World Bank's LSMS, surveys and UNICEF's MICS surveys. The problem is that the number of relevant surveys is limited, although their number is increasing rapidly. ${ }^{23}$ Another possibility could be to use the much more numerous labour force surveys that collect data for persons less than age 15. After further investigation and analysis, this would require reported rates to be adjusted upwards to account for the systematic underreporting of children's economic activity on labour force surveys, although it is expected that the extent of underreporting of children working in wage employment or self-employment should be lower than for all child economic activity (because there is less ambiguity whether this is work as compared to unpaid family work). ${ }^{24} p^{25}$

\section{Forced labour}

Forced labour is defined in ILO Forced Labour Convention, 1930 (No. 29) as "all work or service which is extracted from any person under the menace of any penalty and for which the said person has not offered himself/herself voluntarily". Several forms of forced labour are noted, such as bonded labour, chattel labour, and slavery. In recent years, labour trafficking has become an increasingly important aspect of forced labour. The preamble to the Abolition of Forced Labour Convention No. 105 (1957) points out that forced or compulsory labour constitutes a violation of the rights of man enunciated in the Universal Declaration of Human Rights.

Forced labour is extremely difficult to measure with acceptable precision. This is the major reason why it is not included as a recommended core decent work indicator. First, it is hidden, because it is illegal and immoral. This means that in addition to being difficult

23 ILO/IPEC, for example, will soon have conducted over 40 child labour surveys.

${ }^{24}$ ILO/IPEC (2002) estimates that economic activity of children age 10-14 is underreported on typical labour force surveys by approximately 12 percent, by comparing new ILO global estimates of child labour based largely on special purpose child labour surveys such as SIMPOC with ILO's LABPROJ data based on labour force surveys.

\footnotetext{
${ }^{25}$ One measurement problem worth mentioning and investigating is that some forms of child paid employment may be underreported on surveys even though paid employment of children should be measured more fully on surveys than unpaid family work (since while most people consider wage employment and self-employment as work, many people do not think of unpaid family work on a family farm or family business as work). Surveys may miss paid work performed by children undertaken as part of a family effort, such as in agriculture and construction, where the head of the household is paid and s/he brings along her/his spouse and children to work alongside. Or maids who work for room and board only. Or children who work alongside other family members at home as subcontractors paid on piece rate (see earlier discussion on difficulties in measuring status in employment in the subsection on share of employment in non-agricultural employment).
} 
to find, it would be systematically under-reported using typical household or enterprise surveys. Second, some forms of forced labour, such as debt bondage, are difficult to measure (e.g. it is always not clear at which point an employer-employee relationship becomes forced/bonded, and when an enforcement penalty turns a relationship into bonded labour).

Table 7. Child activity rate by employment status

\begin{tabular}{|c|c|c|c|c|}
\hline \multirow[t]{2}{*}{ Country/Status in employment } & \multicolumn{2}{|c|}{ Male } & \multicolumn{2}{|c|}{ Female } \\
\hline & Age 5-9 & Age 10-14 & Age 5-9 & Age $10-14$ \\
\hline \multicolumn{5}{|l|}{ Kenya } \\
\hline Economic Activity Rate & 4.4 & 8.5 & 4.0 & 7.6 \\
\hline (wage employment plus self-employment rate) & $(0.1)^{b}$ & (1.2) & $(0.1)^{b}$ & (1.5) \\
\hline Wage employment as $\%$ of total c & $2.5^{b}$ & 14.1 & $2.8^{b}$ & 19.7 \\
\hline Self-employment as \% of total & $0.6^{b}$ & $0.7^{b}$ & $0.0^{b}$ & $0.3^{b}$ \\
\hline Unpaid family work as $\%$ of total & 97.3 & 83.6 & 95.1 & 78.8 \\
\hline \multicolumn{5}{|l|}{ Turkey } \\
\hline Economic Activity Rate & $0.7^{a, b}$ & 8.1 & $0.9 \mathrm{a}, \mathrm{b}$ & 5.6 \\
\hline (wage employment plus self-employment rate) & $(0.0)$ & $(4.2)$ & $(0.5)$ & (1.4) \\
\hline Wage employment as $\%$ of total c & $2.5^{b}$ & 45.3 & $5.5^{b}$ & 25.8 \\
\hline Self-employment as \% of total & $0.0^{b}$ & $6.7^{\mathrm{b}}$ & $0.0^{b}$ & $0.0^{b}$ \\
\hline Unpaid family work as $\%$ of total & 97.5 & 47.9 & $94.5^{\mathrm{b}}$ & 74.2 \\
\hline \multicolumn{5}{|l|}{ Namibia } \\
\hline Economic Activity Rate & $14.1^{\mathrm{a}}$ & 16.2 & $10.8^{a}$ & 16.0 \\
\hline (wage employment plus self-employment rate) & $(0.5)^{b}$ & $(1.0)$ & $(0.3)^{b}$ & $(0.6)$ \\
\hline Wage employment as $\%$ of total c & $3.7^{b}$ & 6.1 & $2.8^{b}$ & 3.9 \\
\hline Self-employment as \% of total & $0.1^{b}$ & $0.3^{b}$ & 0.0 & $0.0^{b}$ \\
\hline Unpaid family work as $\%$ of total & 93.1 & 90.3 & 91.5 & 89.9 \\
\hline
\end{tabular}

Notes: Data for 1999. a Ages 6-9. ' Sample size less than 25. c Percentages do not sum to 100 percent, because there is a small "other" category.

Source: ILO SIMPOC, unpublished tabulations.

\section{Further Development}

Since the suggested child labour indicators do not directly measure hazardous or other worst forms of work, future developmental activities should focus on developing indicators to directly measure:

- children in hazardous work (percentage by age)

- children in worst forms of child labour (percentage by age)

Satisfactory indicators for hazardous child labour and other worst forms of child labour will require considerable conceptual development and improvement of survey instruments and other methodologies. Hazardous work, for example, is not only often hidden, it is also difficult to define across countries and over time; indeed, ILO Conventions 138 and 182 leave this to national determination. Furthermore, there are practical difficulties related to the measurement of hazards on surveys (see discussion on measurement in subsection on Safe Work).

Similarly, the highly immoral and illegal nature of the other worst forms of child labour such as prostitution, pornography, armed conflict, trafficking and forced and bonded labour makes it extremely difficult, and perhaps impossible, to measure with 
sufficient accuracy at the national level for a wide range of countries. Due to its importance, however, continued international efforts in this area are warranted.

A long hours of child work indicator for measuring when work by children is likely to interfere with school attendance and performance is not listed as an indicator for future development, mainly because it would require the collection of time use data (since noneconomic activity such as child care and household work is as relevant as economic activity here), and this is felt to be too difficult to do with sufficient accuracy on a sufficiently large scale in many countries. On the other hand, long hours of work (even when it is a combination of paid employment, self-employment, unpaid family work, and unpaid household work), is likely to seriously hinder children's (especially the girl child's) ability to attend and do well at school.

Considering the importance of measuring forced labour for the ILO Declaration on Fundamental Rights at Work together with the difficulty in doing this, the following two approaches to measuring forced labour could be pursued.

- Forced labour extensiveness

It would be possible to collect information on the existence and extent of different forms of forced labour in countries, along with information on actions to reduce forced labour from social partners, governments, ILO's field structure and ILO's supervisory system. If done systematically for every country, this information could be used to develop national indicators for different forms of forced labour in terms of (i) general levels, and (ii) actions toward elimination. For example, a qualitative forced labour indicator could have values corresponding to: none or negligible forced labour, some forced labour, and considerable forced labour. A parallel indicator could gauge efforts to eliminate forced labour. Such qualitative forced labour indicators are not, however, listed as core indicators. It would require substantial resources to set up and maintain a comprehensive, systematic information collection system for all countries, as well as to develop a transparent system for collating, coding and evaluating the collected information.

\subsection{Adequate earnings and productive work}

\section{Background}

For many people, the most important characteristic of work is pay, and the principle of an "adequate living wage" is mentioned in the preamble to the ILO Constitution. Nearly all individuals who work or seek work do so in order to earn an income and ensure the economic well-being of themselves and their households. Besides providing adequate income in the static sense of a decent rate of pay, decent work must also address dynamic aspects of continuing to provide adequate income. One dynamic aspect of decent work is whether individuals are able to improve future work and income via training and further education.

In terms of indicators, adequate pay can be measured directly by an indicator on rate of pay. It can also be measured indirectly through indicators on hours of work that call attention to individuals who work many hours because their rate of pay is not sufficient, or who have limits on their hours of work, resulting in inadequate income. Notice that these indicators mainly rely on distributional data for pay rate and hours of work to identify the percent of workers who: receive inadequate/low pay, have opportunities only for inadequate hours of work, or have long hours of work. The reason for this focus is to help identify workers without decent pay and/or hours. Participation in job-related training 
provided or subsidised by the employer provides an indicator of future earnings possibilities.

\section{Indicators}

Two indicators are suggested to directly measure pay, two indicators to measure aspects of inadequate pay related to hours, and one indicator to measure training as a proxy for future pay opportunities:

- Inadequate pay rate (percent of employed below $1 / 2$ of median or an absolute minimum, whichever is greater, by status in employment)

- Average earnings in selected occupations

- Excessive hours of work (see entry under Decent Hours)

- Time-related underemployment rate (see entry under Decent Hours), and

- Employees with recent job training (percent with job training during last 12 months provided or paid for by employer or state)

The suggested indicators can often be obtained from national labour force surveys, and, therefore, can be compiled based on published tabulations or re-tabulations of existing data for a substantial number of countries. Data for the suggested training indicator are, however, especially limited for developing countries.

\section{Discussion}

Inadequate pay rate

A major decent work concern as regards pay is that workers should have an adequate level of pay. For this reason, the focus here is on the percentage of workers with low pay, since it is felt that this is more appropriate for measuring and monitoring decent work deficits than is an indicator of average levels of pay. This implies that a new indicator needs to be developed and measured, since almost all pay data that are available internationally measure average pay.

In order to clearly distinguish between the rate of pay and the amount of work performed, the indicator is formulated in terms of hourly earnings, defined as rate of gross earning $^{26}$ for one hour of work. Hourly earnings below half of the median are considered to be low. The concept is illustrated in Figure 1. By setting this value with respect to the distribution of hourly earnings in each country, an attempt is made to accommodate differing national norms about "decency" of pay. Since the median of the distribution reflects the relative position of a typical worker in that distribution, it is plausible that national norms for what constitutes decent pay are tied to the median. Furthermore, formulating the indicator in terms of a specific percentage of the median earnings makes it independent of national currencies and therefore facilitates international comparison.

\footnotetext{
${ }^{26}$ See Resolution concerning an integrated system of wages statistics, adopted by the Twelfth International Conference of Labour Statisticians (October 1973), paragraphs 8-10, in Current International Recommendations on Labour Statistics 2000 Edition, ILO, Geneva, 2000, pp. 44-45.
} 


\section{Figure 1. Distribution of employees by gross hourly earnings.}

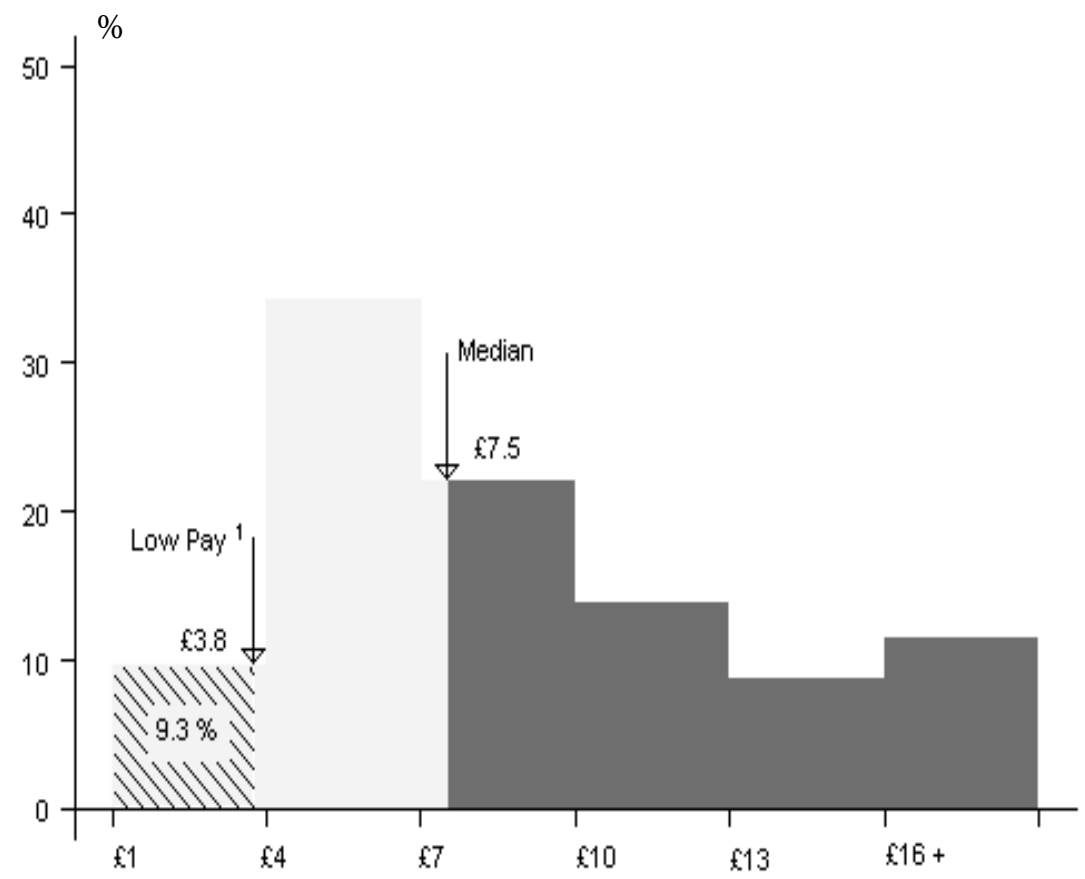

Note: ${ }^{1}$ Low Pay is defined as fifty percent of median $(1 / 2 £ 7.54=£ 3.77)$. It should be compared with the National Minimum Wage (NMW), since April $1999, £ 3.00$ for those $18-21$ year olds and $£ 3.60$ for those aged 22 and over with some exception for workers receiving accredited training during the first six months with a new employer.

Source: Office for National Statistics, United Kingdom, Labour Force Survey Quarterly supplement, Autumn (September to November 2001), No. 16, February 2002, Table 36.

While the choice of 50 percent is debatable, it has the advantage of simplicity. It is consistent with minimum wage rates in OECD countries where the minimum wage is often established through democratic processes and turns out to be reasonably close to half of the median wage (national values vary from about 25 percent to 50 percent in OECD countries). ${ }^{27}$ Another advantage of the definition is its wide applicability, including in countries that have either not adopted minimum wage legislations or have set the statutory minimum wage below the prevailing market wages that would make calculations based on it virtually meaningless. A possible disadvantage of the methodology is that it is possible over time for the pay rate determined by 50 percent of the median to indicate an increase in the percentage of workers with a low pay rate in a situation where the real pay of low paid workers has risen.

It would, therefore, also be useful to monitor the real value of the pay rate for workers in the lowest pay rate decile. ${ }^{28}$ Based on experience in the future with low pay rate indicators, it should become possible to decide on whether these additional statistics on the situation of workers in the lowest decile should be added to the core list of ILO decent work indicators.

Since no society would regard as "decent" a pay rate that results in unacceptable poverty, an absolute minimum floor is needed for countries where the indicator would

\footnotetext{
${ }^{27}$ OECD Employment Outlook, 1997.

${ }^{28}$ Since construction of the inadequate pay rate indicator requires information about the distribution of earnings, little additional effort would be needed to track the first decile value or similar statistics.
} 
otherwise establish the decent pay rate below such a level. One approach would base the threshold on national poverty lines or the cost of minimum food requirements. Either alternative presents practical difficulties for internationally comparable indicators that would take some time and resources to overcome, though either would be relatively easy to use in specific countries. An alternative approach the widely accepted World Bank poverty rate of $\$ 2$ per day. Although the calculation could be based on $\$ 1$ per day, we prefer \$2 per day on the principle that the \$1 per day level is an indicator of "extreme" poverty, so the corresponding wage rate cannot reasonably be termed "decent." The following logic is suggested for calculating the absolute minimum hourly pay rate using the $\$ 2$ pre day rate. Decent pay should allow a full-time worker to support at least one person besides himself or herself at a level above the World Bank's and UN's \$2 per day per person poverty line (though the World Bank actually uses $\$ 2.15$ per day). Defining "full-time" for this purpose as 8 hours per day, six days per week and 50 weeks per year, means that 2400 hours of work ( 8 X 6 X 50) should produce at least $\$ 2.15 \times 2$ persons X 365 days $=\$ 1569.50$ of earnings, corresponding to an hourly rate of $\$ 0.65$. The translation of earnings rates from local currency to U.S dollars should use the World Bank's purchasing power parities. This simple calculation is conservative, as it assumes long hours, a small dependency ratio, and a poverty-level income requirement. The conservative approach is consistent with a reluctance to impose absolute limits for decent pay. It could be argued, however, that the dependency ratio used should be based on regional or national data, which would increase the multiplier in most of the relevant countries.

In principle, a job is the statistical unit for measuring the low pay indicator. Measurement of the low hourly pay rate indicator requires for each economic activity, data on status in employment pay period, gross earnings last received in the case of paid employment and gross income related to self-employment currently earning in the case of self-employment, and hours of work. The measurement should account for situations in which a person changed jobs, started a new job, or quit their job within the normal pay period. Implementation will often require compromises, as full measurement at present will be difficult in most regular labour force surveys. For example, a person with more than one job could be classified as having low pay rate with respect to one job, and decent pay rate with respect to another.

The most straightforward calculation would be based on direct questions about the hourly rate of pay, but this faces some practical difficulties. First, for employees, the rate of pay is often set for a different interval than one hour. ${ }^{29}$ In this case, it is necessary to divide gross earnings by an appropriate multiple of weekly hours of work. Second, for self-employed persons and contributing family workers, the calculation of hourly earnings is problematic as both earnings and hours of work are especially difficult to define and measure. For this reason, many national labour force surveys limit the measurement of earnings to employees only.

The following table presents data for Jordan and the United Kingdom. Despite elements of non-comparability, the results show that the percentage of workers with low pay rate was higher in Jordan than in the United Kingdom by a wide margin.

The gender comparison is based on the assumption and calculation that the decent pay threshold should be the same for men and women. The results show that in Jordan a lower

\footnotetext{
${ }^{29}$ In certain countries, the reported statistics on hourly earnings are limited to the sub-category of employees paid on hourly rates.
} 
percentage of women workers as compared to male workers have low pay whereas the opposite is true in the United Kingdom. ${ }^{30}$

Table 8. Percentage of workers with gross hourly earnings below half of median

\begin{tabular}{lccc}
\hline Country & Both Sexes & Male & Female \\
\hline Jordan (November 2001) & 15.4 & $15.7(86.7)^{3}$ & $13.7(13.3)^{3}$ \\
United Kingdom (Autumn 2001) & 9.3 & $8.7(64.2)^{3}$ & $10.6(35.8)^{3}$
\end{tabular}

Notes: ${ }^{1}$ Covers all employed persons except unpaid family workers. Percentages calculated on the basis of grouped data cross classified by interval of monthly earnings at all jobs and of actual hours worked during the week. ${ }^{2}$ Limited to employees only. Percentages calculated on the basis of a trimmed decile distribution of gross hourly earnings (employees whose hourly pay is $£ 100$ or over were excluded from the sample). ${ }^{3}$ Figures in parentheses refer to share of male or female employment in total low pay employment.

Sources: The Hashemite Kingdom of Jordan, Department of Statistics, Employment and Unemployment Survey (Fourth Round) November 2001, Principal Report, January 2002, Table 7/3. National Statistics Office, United Kingdom, Labour Force Survey Quarterly supplement, Autumn (September to November 2001), No. 16, February 2002, Table 36.

\section{Average earnings in selected occupations}

Occupational earnings or wage data from establishment surveys or other reliable sources are particularly useful for comparing wage trends, and wage differentials between different categories of workers. Trend comparisons help identify relative wage drifts in specific occupations, i.e., the extent to which the wages in one occupation over a period of time have changed more (or less) than wages in other occupations. Differential comparisons help measure and explain wage differentials between men and women in the same occupations, wage differentials between workers with different skill-level occupations, and wage differentials between occupations which are or are not exposed to international trade pressures

The choice of the specific occupations selected for the present purpose should be carefully considered. Possible criteria include: male-dominated and female-dominated occupations; occupations in tradable sectors and in non-tradable sectors; skilled and low skilled occupations. In this way, it would be possible to measure and monitor differentials in wages according to skill level, exposure to international trade, and feminisation.

The ILO October Inquiry on Statistics on Occupational Wages and Hours of Work data, which have been collected since 1921 and now cover 159 occupations in 49 industry groups, provide a basis for compiling relative average wage indicators. The ILO Key Indicators of the Labour Market has calculated occupational wages and earning indices for six occupational groups from the ILO October Inquiry to reflect varying skill levels in different sectors of activity: (1) labourer in construction; (2) welder in metal manufacturing; (3) professional nurse; (4) first-level education teacher; (5) computer programmer in the insurance sector; and (6) accountant in the banking sector. This set of occupational groups should be revisited and, depending on data availability and data quality, and other occupations such as the following should also be considered: agricultural labourer (low skilled occupation); engineer (skilled male-dominated occupation); sewing machine operator and electronic equipment assembler (tradable sector occupations, female-

\footnotetext{
${ }^{30}$ The appropriate method of subgroup comparison should be examined for each variable in future work. For example, comparison of the low pay indicator for agricultural and non-agricultural workers might possibly use the pay distributions of the two groups separately, implicitly assuming different decent pay thresholds for agricultural and non-agriculture workers, in line with the assumed differences in the cost and levels of living in rural and urban areas.
} 
dominated occupations); typist/stenographer, and retail trade (non-tradable sector occupations, with former female-dominated).

October Inquiry data, however, have a number of serious problems. First and foremost, they are very incomplete and inconsistent (Freeman and Oostendorp, 2001) ${ }^{31}$ in that national data are reported for different pay periods (e.g., per hour, week and month), pay definitions (e.g., actual wages, actual earnings, and statutory pay rates), and sources (e.g. labour force surveys of all workers and large modern establishments). In addition, data are sometimes reported for men and women separately and sometimes only for total workers. This makes it difficult to consistently obtain standardised values (e.g., say earnings per hour for men and women separately). Further reducing the effectiveness of the October Inquiry data is that while pay rates are reported, employment is not. As a result, it is not possible to ascertain pay for all workers when data are reported only for men and women separately (as is common). It is clear that considerable work will be necessary to develop usable relative pay indicators from the October Inquiry data. It is also important that efforts increase to improve the standardisation of these data through correspondence with national statistical offices, as well as to collect complementary employment data by sex. Work by Robinson $(1998)^{32}$ and Freeman and Oostendorp (2001) demonstrates the usefulness of these unique October Inquiry data.

Table 9 demonstrates one possible use of these data, to measure relative levels and changes for gender inequality. The rather dramatic changes in female-male wage ratios that occurred in a few years in some cases seem implausible and reduce one's confidence in these data. Although this could be due to sampling variability (especially for genderdominated occupations with few men or women), the October Inquiry publication does not presently provide enough information to ascertain this. For example, these data implausibly indicate that in Thailand the gender gap for accountants and computer programmers closed dramatically in only four years, while rising dramatically for construction labourers.

31 Freeman, R.B. and Oostendorp, H. "The occupational wages around the world data file", International Labour Review, Vol. 140, No. 4, 2001.

32 Robinson, D. "Differences in occupational earnings by sex", International Labour Review, Geneva, ILO, Vol. 137, No.1, 1998. 
Table 9. Ratio of women's to men's wages, selected occupations

\begin{tabular}{lcccccc}
\hline Occupation/Industry & \multicolumn{2}{c}{ Thailand $^{1}$} & \multicolumn{2}{c}{ Romania } & \multicolumn{2}{c}{ Finland } \\
& 1991 & 1995 & 1995 & 1999 & 1990 & 1997 \\
\hline Labourer, construction & 0.92 & 0.75 & 0.97 & 0.96 & 0.85 & 0.79 \\
Welder, metal manufacturing & 0.72 & 0.71 & 0.89 & 1.02 & 1.01 & 0.92 \\
Professional nurse & 0.95 & 1.14 & 0.93 & 1.02 & 1.00 & 0.98 \\
First-level education teacher & 1.06 & 0.92 & 0.96 & 0.88 & 0.99 & 0.96 \\
Computer programmer, & 0.68 & 0.98 & 1.03 & 0.68 & 1.01 & 0.86 \\
insurance & & & & & & 0.96 \\
Accountant, banking & 0.64 & 0.90 & 0.97 & 0.96 & 0.90
\end{tabular}

Notes: ${ }^{1}$ Data refer to Bangkok only. ${ }^{2}$ Data for 1994 rather than 1995.

Source: Key Indicators of the Labour Market based on ILO October Inquiry data.

Training

Training and education are forms of investment in human capital, improving skill and increasing the likelihood of future employment and remuneration. Workers see training as an element of career development and higher future earnings. Employers expect to benefit from the higher productivity that training gives their employees. Participation in jobrelated training may, thus, be regarded as an indicator of decent work and future earnings. And its provision or subsidy by an employer would be one element of a decent job.

This aspect of decent work can be measured by the percentage of employees who participated in job-related training provided or subsidised by an employer over the last 12 months. The scope of the indicator is limited to employees, although it could be extended to the self-employed where appropriate. In certain countries, there are many training programmes for the self-employed, for example on management, marketing, financing etc. In principle job-related training includes courses, workshops, and training programmes on areas related to the job of the participant. For example, training in computer software may be considered job-related if its knowledge is required for the job or if it helps the performance of the tasks and duties of the job. Training on topics of personal interest if unrelated to the job would be excluded. Although on-the-job training that is not formalised could also be included, it is difficult in practice to determine when on-the-job training is more than usual work experience. One simple criterion for deciding on such inclusion or exclusion may be "enrolment" in a formal training programme.

It is convenient to use a one-year reference period for measuring job-related training based on a survey question. Job-related training is not a frequent event and, therefore, a shorter reference period (such as one week or one month) would lead to a limited number of observations, impairing the reliability of the estimates. For a similar reason, it is suggested to include job-related training of any job-related training during the reference year, regardless of duration. To specify a duration-threshold would be arbitrary and, in any case, OECD data suggest that job-related training of very short duration, such as a day or two days, is rare (OECD 1998). Finally, in order to focus on "decent work" and avoid the inclusion of the many participants of employment-training programmes and related labourmarket measures instituted by governments to combat youth unemployment, it is proposed to limit the indicator to the age category 25 to 64 years, 25 to 44 years, or 25-54 years.

Data for Jamaica, Poland and Canada are presented below. The data include participation in job-related training, whether or not it is employer-provided. Approximately 40 percent of employed persons 25-44 years-old participated in job-related 
training during the year in Canada. The percentage is substantially lower, but nevertheless substantial in both Jamaica and Poland. It can also be noted that the observed percentages are similar for the 25-44 and 25-64 age groups for the two countries that report data by age group. ${ }^{33}$

Table 10. Percentage of employed persons participating in job-related education or training during the previous year

\begin{tabular}{lccc}
\hline Country & \multicolumn{1}{c}{ Age } & $\mathbf{2 5 - 6 4}$ \\
\cline { 2 - 4 } & $15+$ & $\mathbf{2 5 - 4 4}$ & 17 \\
\hline Jamaica ${ }^{2}$ & $16^{1}$ & 17 & 38 \\
Poland & & 41 & \\
Canada $^{3}$ & & & \\
& & \\
Notes: & 1 Persons who reported to have received special training for their current job, excluding on-the-job training: 13\% among men and 20\% among \\
women. ${ }^{21997 .}{ }^{3}$ 1994-95 & \\
Sources: The Statistical Institute of Jamaica, The Labour Force 1997, Kingston, 1998, p. 54. OECD Centre for Educational Research and \\
Innovation, Education at a Glance. OECD Indicators 1998, Table C5.2, Paris 1998.
\end{tabular}

Data on this indicator for developing countries appear to be scarce at present. While a number of developing countries ask about training in their labour force survey, the question often refers to whether the person has ever received training (rather than to a fixed reference period) and rarely inquires about whether the training was provided by the employer. For this reason, retention of this suggested training indicator in the ILO core set of decent work indicators will depend on further investigation.

\subsection{Decent hours}

\section{Background}

Concern with hours of work has a long history at the ILO-the issue is raised in the preamble to the ILO Constitution, and is addressed by the first ILO Convention, the Hours of Work (Industry) Convention, 1919 (No. 1). In contemporary terms, at least four aspects of decent work can be linked to hours of work. Excessive hours and atypical hours can be detrimental to physical and mental health and they impede balance between work and family life. Excessive hours are frequently a signal of inadequate hourly pay. Short hours can indicate inadequate employment opportunities.

\section{Indicators}

The suggested indicators are:

- Excessive hours of work (percent of employed, by status in employment), and

- Time-related underemployment rate (percent of employed population working less than hours threshold, but available and wanting to work additional hours).

Hours of work estimates are available from virtually all labour force surveys, but there are several reasons why international comparability is a serious problem. Hours data

\footnotetext{
${ }^{33}$ Additional data from the publication Education at a Glance OECD Indicators 1998 show a high correlation between the incidence and average duration of job-related training. This means that countries with high training rates tend to be countries with relatively high average duration of training. If this result can be generalized to non-OECD countries, it would suggest that participation rate is a sufficient indicator to show both incidence and duration of training.
} 
may refer to actual hours worked or usual hours worked, to hours on all jobs or only at the main job. And, few countries presently collect data on reasons for working short hours, or availability for and willingness to work additional hours (two criteria for defining timerelated underemployment).

\section{Discussion}

\section{Excessive hours of work}

The share of workers with excessive hours is a useful indicator of several aspects of decent work. Excessive hours of work are a threat to physical and mental health, interfere with the balance between work and family life, and often signal an inadequate pay rate. Excessive hours also reduce productivity. Yet many people work long hours on a regular basis and their number appears to be increasing despite lower normal hours of work in many countries. ${ }^{34}$ ILO Convention No. 1 specifies that hours of work per week should not exceed 48, although a 60-hour week was accepted as the principle for then British India.

Most national labour force surveys that publish detailed data on the upper tail of the distribution of weekly hours of work use 50 (or 49) hours for the lower bound of the penultimate interval and 60 hours for the last interval. It is inconvenient to use two thresholds for the number of hours and distinct terminologies for the corresponding indicators: (a) excessive hours of work - persons working 49 or 50 hours or more per week; and (b) extreme hours of work - persons working 60 hours or more per week. The former is essential in line with the requirement of the ILO Convention No. 1, and the latter takes into account the generally longer working hours reported by the self-employed.

Table 11 compares available data for Turkey and the United States. More people worked long hours in Turkey than in the United States, and the difference is particularly striking in the category 60 hours of work or more. If it is confirmed in a broader selection of countries, the usefulness of a 60 hour threshold in addition to a 50 hour threshold would be desirable.

34 According to Professional Update Vol. 11, No. 6. Nov/Dec 2001, 30 percent of full-time employees in Australia work 49 hours or more per week, compared to 19 percent in 1978 (http://www.apesma.asn.au/newsviews). Another example is the reported rise of the phenomenon of Karoshi (death from overwork) in Japan due to cases of cardio-vascular disease brought on by excessive workload and occupational stress, National Defence Counsel for Victims of Karoshi, Karoshi When the “Corporate Warrior” Dies, Tokyo, Mado-Sha, 1990. 
Table 11. Percentage of persons with long hours of work

\begin{tabular}{lcc}
\hline Country & Actual hours worked at all jobs during the reference week \\
\cline { 2 - 3 } & $\mathbf{5 0 - 5 9}$ hours ${ }^{1}$ & $\mathbf{6 0}$ hours and over \\
\hline Turkey (October 1994) & 12.2 & 25.2 \\
United States (2001) & 10.8 & 7.8 \\
& & \\
Note: ${ }^{1}$ In the United State, the lower limit of the interval is 49 hours of work. & \\
Sources: Turkey State Institute of Statistics, Household Labour Force Survey Results, October 1994, Ankara, June 1996, Table E-14. US Bureau of \\
Labour Statistics, Employment and Earnings, Washington, D.C., January 2002, Vol. 49, No. 1, Table 19, p. 193.
\end{tabular}

An excessive hours indicator will be sensitive to a number of factors besides actual hours worked. First, the degree of accuracy in the measurement of hours worked varies among countries. Hours of work are notoriously difficult to measure in surveys, especially when proxy responses are admitted. Even in the case of self-response, there is a tendency to over-report hours of work by all categories of workers, and the extent of this bias potentially differs among countries. Second, some of the variation among countries can be attributed to differences in the share of self-employment in total employment. Selfemployed persons have more freedom in choosing their work schedules and tend to report higher hours of work, partly because their economic activity is easily confounded with non-economic activities. For example in family farms, agricultural activities are often intermingled with domestic chores. Third, some countries report usual hours of work rather than reference-week hours. Though less commonly measured, usual hours is conceptually preferable for the present purpose; occasional long hours are less likely to be detrimental than persistent long hours and less likely to be a sign of inadequate pay rather than temporary fluctuations in business needs.

In many cases, excessive hours of work occur for economic reasons. Most people who combine two jobs or more are doing so because the pay in any one job is not sufficient to maintain their family's well-being. Also, many workers who work overtime and at odd hours do so to earn extra income. To extract from work hours as much information as possible about inadequate pay, an indicator measuring excessive hours of work for economic reasons would be useful. ${ }^{35}$

- Excessive hours of work for economic reason by status in employment

The proposed qualifier, "for economic reasons," is intended to separate this phenomenon from long or excessive hours of work for voluntary reasons such as ambition or passion for work, or other involuntary reasons such as nature of the work, exceptional circumstances, corporate norms, etc. In practice, however, it may prove to be difficult to make a distinction between excessive hours for "voluntary" and "economic" reasons. No national survey could be found that collects data on long or excessive hours of work for economic reasons.

35 This concept should be distinguished from the concept of inadequate employment related to excessive hours introduced at the Fifteenth International Conference of Labour Statisticians, that refers to situations "where persons in employment wanted or sought to work less hours than they did during the reference period, either in the same job or in another job, with a corresponding reduction of income." Although important, this phenomenon occurs mainly among women with young children working on full-time schedules who would prefer part-time work even at the cost of reduced earnings in order to spend time at home for child caring. 


\section{Time-related underemployment}

For virtually all workers, earnings are adequate only if a sufficient number of hours can be worked. From a macroeconomic perspective, underemployment is similar to unemployment - the economy's labour resources are under-utilised if employed people are working fewer hours than they desire. Labour statisticians have termed the phenomenon time-related underemployment. The standard definition specifies that "hours of work of an employed person are insufficient in relation to an alternative employment situation in which the person is willing and available to engage". ${ }^{36}$ The definition is operationalised by three criteria that should be satisfied simultaneously: "willing to work additional hours"; "available to work additional hours"; and "worked less than a threshold relating to working time" during the reference period. The international definition does not specify the value of the hours threshold, but suggests that it can be chosen according to national circumstances.

Data availability for time-related underemployment appears to be poor. Although over 50 countries collect information related to visible underemployment in national household-based surveys, there is great variety in the information collected and therefore the criteria that could be used to define underemployment. ${ }^{37}$ According to the notes for statistics presented in Key Indicators of the Labour Market (KILM), only 14 developing countries have data that can be called time-related underemployment. This means that the data for developing countries are scarce and not comparable to the data for industrialized and transition economies. Australia and the Czech Republic estimate the number of underemployed and publish the results as part of their national labour force survey programmes. The data for these two countries are shown in Table 11. According to these results, the underemployment rates in these countries are smaller than the unemployment rates (5.9 percent in Czech Republic and 6.1 percent in Australia, for all workers in the respective years). In both countries, the underemployment rate is higher among women than men, probably because more women are working part-time.

In both countries, the underemployment rate is higher among women than men, probably because more women are working part-time.

36 Resolution concerning the measurement of underemployment and inadequate employment situations, adopted by the Sixteenth International Conference of Labour Statisticians (October 1998), op. cit., paras. 7-9.

37 ILO, "The measurement of underemployment", $16^{\text {th }}$ International Conference of Labour Statisticians, ILO, Geneva. 1998, Annex 3. 
Table 12. Percentage of underemployed workers among the employed population

\begin{tabular}{lccc}
\hline Country & Both sexes & Male & Female \\
\hline Czech Republic (1998 Q1) & 1.3 & 0.3 & 2.5 \\
Australia $(2000)^{2}$ & 4.8 & 3.8 & 6.2
\end{tabular}

Notes: ${ }^{1}$ The underemployed comprises all employed persons, except those not at work for more than four weeks, who were working part-time during the reference week due to (a) not being able to find an appropriate full-time job; and (b) the initiative of the employer. ${ }^{2}$ The underemployed comprises three categories: (a) Employed persons who worked less than 35 hours in the reference week for economic reasons; (b) Part-time workers looking for and available to work more hours; and (c) Part-time workers not looking for work, but available to work more hours.

Sources: Czech Statistical Office, Employment and Unemployment in the Czech Republic as measured by the labour force sample survey 1st quarter (January to March 1998), Prague, 22 June 1998, Tables 309 and 201. Australian Bureau of Statistics, Measures of Labour Underutilisation, Information Paper 6296.0, Canberra, 27 February 2002, Table 1, and ILO Yearbook of Labour Statistics 2001, Geneva, 2001, Table 2A.

It is also instructive to note that the underemployment rate is higher in Australia than in the Czech Republic. The pattern of higher time-related underemployment rates in high income countries as compared to the other countries may appear counter-intuitive, but can be substantiated with data from other countries (Turkey, 1.6 percent; Thailand, 2.2 percent; Jamaica, 2.4 percent; Japan, 7.4 percent; United Kingdom, 9.4 percent; and United States, 11.8 percent). ${ }^{38}{ }^{39}$ The pattern probably occurs because a higher share of self-employment in developing countries reduces the base for time-related underemployment, which affects primarily employees.

Should this indicator be developed further, it would be desirable to move toward a uniform procedure for determining the threshold for short time work. Alternatively, a proxy possibility for time-related underemployment could be defined as the total of two categories of workers: (a) persons who usually work part-time schedules (to be specified according to national conditions) and want to work additional hours; and (b) persons who worked fewer than their normal hours of work for economic reasons during the reference period.

\section{Atypical or asocial hours}

The percentage of workers who work atypical or asocial hours would be a useful complementary hours indicator, though at present, such data are collected primarily for

38 The national definitions vary somewhat in this list, particularly in the hours threshold (33 to 40 hours). However, the higher hours thresholds do not correspond to the higher underemployment rates in this list.

\footnotetext{
${ }^{39}$ Turkey: Persons working less than 40 hours per week and seeking another job, as replacement to present job or as an additional job. State Institute of Statistics, Household Labour Force Survey Results, October 1994, Ankara, June 1996, Table 26. Thailand: Persons working less than 40 hours during the reference week and available for additional work, National Statistical Office, Report of the Labour Force Survey, Whole Kingdom, Round 2, May 1998, Bangkok, 1998, Table 10. Jamaica: Persons working less than 33 hours during the reference week because only part-time was available or because of labour dispute. The Statistical Institute of Jamaica, The Labour Force 1997, Kingston, 1998, Table 3.9. Japan: Persons who worked less than 35 hours during the last week of February and wished to change job, or wished to have additional jobs, or wished to have more work time in the present job. Statistics Bureau, Report of the Special Survey of the Labour Force Survey, February 2001, Labour Force Series No. 67. Tokyo, August 2001, Table 7. United Kingdom: Persons wanting to work longer hours in current job, in different job, and in additional job, Office of National Statistics, "Using the Labour Force Survey to estimate time-related underemployment," Labour Market Trends, London, August 1999, pp. 417-423. United States: Annual average number of persons at work 1 to 34 hours in the reference week in 2001 for economic reasons: slack work or business conditions, could only find part-time work, seasonal work, job started or ended during week. US Bureau of Labor Statistics, Employment and Earnings, Washington, D.C., January 2002, Vol. 49, No. 1, Table 20, p. 193.
} 
industrialized countries. The pattern of hours can affect the balance between work and family life as well as physical and mental health. ${ }^{40}$ In the development of such an indicator, several aspects should be considered: time of day, especially if at night; weekend work; and how frequently work schedules change.

- atypical or asocial work hours

Consideration should also be given to differences in social norms and individual preferences, since these affect which patterns of hours are regarded as atypical or asocial.

\subsection{Stability and security of work}

\section{Background}

Losing one's job or work is a serious event for most people, and there is little doubt that job security is seen by most people as an important aspect of decent work. Job loss involves economic costs beyond loss of pay, even if a new job is found quickly. Changing jobs disrupts the process of human capital accumulation, potentially making worthless the knowledge and skills specific to the lost job. Changing jobs also frequently disrupts access to benefits, particularly pensions. Finally, job change disrupts other parts of the individual's life. For example, the entire household may be forced to relocate to find or accommodate new work. In addition, the threat of job loss causes stress.

Job security indicators have a number of problems. They are difficult to measure as discussed below. Interpretation is complicated because the consequences of job loss are moderated by various factors, some addressed by other decent work indicators: A high unemployment rate implies that income loss is likely to be prolonged. The availability of training, either prior to or following job loss, improves the prospects for finding new work. Unemployment insurance and severance payments, where applicable, replace some of the lost income. Advance notice requirements give an employee time to find replacement work before the income loss begins.

Although individuals value job security, development and growth necessarily entail some degree of job insecurity that stems from the contraction or disappearance of occupations, firms and industries (and the growth or appearance of others). In addition, workers sometimes change jobs voluntarily. Job security as part of decent work must be understood in this context. ${ }^{41}$

\section{Indicators}

The suggested indicators are:

- Tenure less than one year (percent of employed persons who have held their main job/work for less than one year, by age, by status in employment), and

${ }^{40}$ See, for example, Daniel S. Hammermesh, "Changing Inequality in Work Injuries and Work Time," Monthly Labor Review, October 1999, pp. 22-30.

${ }^{41}$ Decent work policies intended to improve job security should be concerned with protecting workers from bearing an unfair share of the economic risk inherent in economic activity or with assisting them in a transition to new work. Specific policies intended to directly improve job security may or may not conflict with growth. If they do conflict, the trade-off may, nevertheless, be deemed desirable by society. 
- Temporary work (percent of employees who classify their jobs as temporary).

Data on job tenure and temporary status are generally available from labour force surveys for OECD countries. Data are limited, however, for developing countries.

\section{Discussion}

Job security for an employee can be defined as the probability that the current employment relationship will not end within a certain period (one year, for example) at the employer's initiative. For a self-employed individual, job (work) security can be defined as the probability that the worker will not be forced to end his or her work within a certain period for reasons connected with the work (as distinct from personal circumstances). Whether or not it is made explicit, deciding on a "decent" level of job security amounts to choosing a horizon over which the probability of continuing work is sufficiently high.

Since its definition involves a probability rather than an actual event, job security must be measured indirectly. Four types of job security indicators have been considered. First, an indicator of past employment stability, such as tenure (time on the present main job/work), is often considered to be a good predictor of future stability. Second, for employees a permanent/indefinite job is usually more secure than an explicitly temporary job. Third, a worker's perception of his or her job security over a fixed horizon provides an indication of future employment stability. Fourth, the intermittency of a worker's employment during some past period longer than a reference week should generally predict a similar future pattern.

Job tenure

Indicators based on job tenure share certain disadvantages. First, long tenure and a secure job in the past do not necessarily indicate future security, especially in periods of rapid economic transition or downturn.

Second, short tenure does not necessarily indicate low job security, especially for younger workers, who have short tenure whether or not their jobs are secure. This observation implies that statistics summarizing job tenure for all workers in a country (e.g., mean or median tenure) are sensitive to the demographic structure of the labour force, affecting international and intertemporal comparisons. ${ }^{42}$

Third, job tenure indicators are not likely to be useful in judging changes in job security during business cycles. Since short-tenure workers are more likely than longtenure workers to lose their jobs during a downturn, average tenure will rise making it appear that job security has risen. Conversely during a recovery, newly hired unemployed workers start with zero tenure, and so job security appears to have fallen.

\footnotetext{
${ }^{42}$ A similar issue arises in comparing job tenure of men and women. Women are more likely to leave the labour force for some part of their adult lives. When they re-enter, they initially have short tenure, regardless of the security of their jobs. This phenomenon has two related implications for a job tenure indicator. First, although women returning to the labour force may have somewhat lower job security, the magnitude of this reduction is exaggerated by a statistic that, in effect, treats them all as initially having job security equivalent to casual workers. Second, the prevalence of women choosing to leave the labour force temporarily varies internationally because of different fertility patterns and social norms. Measured overall job security for two countries might differ because of this even if the job security of workers who follow uninterrupted career paths is identical.
} 
Recognizing these difficulties and data availability, the suggested indicator of job security is the percentage of employed workers with job tenure of one year or longer. The one-year threshold could be considered to correspond to decent or adequate job security, although this is a subjective judgement. Using one year as the cut-off mitigates, though does not eliminate, the effect of demographic structure of the labour force. ${ }^{43}$

\section{Temporary work}

The second suggested indicator is based on labour force survey questions that essentially distinguish temporary from non-temporary jobs, though the exact approach varies. Questions along these lines are used in many developed and some developing countries. The temporary/not temporary distinction is not typically a direct question about contract status; in most countries the question does not refer to contracts. Instead, available data are based mainly on questions that ask whether a job is temporary versus permanent/indefinite, with "temporary" not defined in the wording of the question.

On average, temporary jobs are less secure than permanent/indefinite ones, though exactly how much more insecure is not well known. ${ }^{44}$ Because the economic and legal distinctions between temporary and permanent and the wording of survey questions differs among countries, international comparability of this indicator is limited at present. To put this ambiguity in context, it should also be noted, that for the entire European Union (EU) according to EUROSTAT data nearly 40 percent of temporary workers expected their jobs to have a duration of greater than one year-a duration that many observers might not consider "temporary". 45

The temporary status indicator could be refined in two directions with improved data collection. Distinctions could be made among temporary employees with respect to the duration of their jobs (already done on the EU labour force survey), or a questionnaire could identify jobs that are effectively temporary, whether or not respondents would describe their jobs as temporary. The United States has introduced the latter refinement, as indicated in the footnotes to Table 13.

Table 13 illustrates some of the difficulties in measuring job security. The most striking is the position of the United States-offering the lowest job security according to the job tenure indicator and the highest job security according to the temporary employment indicator. Although this anomaly is partly caused by the special structure of individual countries' labour markets, it also highlights the fact that there are significant

${ }^{43}$ Data from the United States, Current Population Survey for February 2000 can be used to illustrate this point. In the 16-19 year age group, 75 percent of employees had tenure of one year or less, while only 11 percent of those in the 55-64 age group had tenure of a year or less. Holding constant the patterns of job tenure in each age group, and shifting one percent of wage employment from the older group to the younger, would change the value of the job tenure indicator by 0.64 percentage points $(=0.75-0.11)$.

${ }^{44}$ In principle, this is not difficult to observe statistically for a given country at a given time. One need only compare how many permanent employees remain with the same employer a year later with how many temporary employees remain with the same employer. This suggests that the indicator can be gradually made more useful by studies that benchmark the difference in different countries.

45 The calculation is based on temporary workers who answered a follow-on duration question. About 27 percent of temporary workers did not answer the duration question, which suggests the additional ambiguity that it is not always easy for workers to know how long a temporary job is likely to last. 
international inconsistencies in how the concepts are defined and data are collected, as well as the fact that neither indicator is directly measuring job security.

Table 13. Job security

\begin{tabular}{lcc}
\hline Country & $\begin{array}{c}\text { Percent of employed with tenure of 1 } \\
\text { year or less }\end{array}$ & $\begin{array}{c}\text { Percent of employees who are } \\
\text { temporary }\end{array}$ \\
\hline Finland & $19.7(1998)$ & $20.9(2000)$ \\
United States & $26.8(2000)^{\mathrm{b}}$ & $4.3(2001)^{\mathrm{c}}$ \\
Poland & $(\mathrm{a})$ & $5.8(2000)$ \\
Brazil & $18.2(1999)^{\mathrm{d}}$ & $\mathrm{NA}$ \\
Philippines & $\mathrm{NA}$ & $21.4(1998)$
\end{tabular}

Notes: a Collected, but not readily available. ${ }^{b}$ Employees only. ${ }^{c}$ According to the U.S. Bureau of Labour Statistics, this estimate of what is termed contingent employment, "effectively includes all the wage and salary workers who do not expect their employment to last, except for those who, for personal reasons, expect to leave jobs that they would otherwise be able to keep". The estimate includes self-employed workers who meet certain criteria. d Tenure of 11 months or less. Next interval in published source is 1-2 years.

Sources: Eurostat, U.S. Bureau of Labour Statistics, Instituto Brasileiro de Geografia e Estatística (IBGE), Philippines Bureau of Labour and Employment Statistics.

\section{Further development}

Two additional approaches and indicators appear to be worth additional investigation:

- perceptions of future job security, and

- measures of intermittency of employment.

Data on perceptions of future job security have been collected by nongovernmental sources in some countries. ${ }^{46}$ Where available, data are based on a survey question similar to, "Thinking about the next 12 months, how likely do you think it is that you will be able to keep your main job if you want to?" Data generated by a question like this has the advantage that it incorporates workers' understanding of their own situation. ${ }^{47}$ In periods of change (e.g., globalisation), this feature of the indicator is especially useful. The drawback of an indicator based on subjective judgement is that it may incorporate systematic psychological biases unrelated to the objective situation; although fear of job loss is important in its own right, it is not the same thing as the actual risk of job loss. Further research is needed to understand the nature of the relationship between actual and perceived job security.

The temporary status indicator discussed earlier measures the employer's intent for a particular job/employee (though, in reality, the meanings attached to "temporary" by respondents may encompass a wider set of considerations). The tenure indicator focuses on the history of a specific employer-employee relationship. Because of the focus on a specific job, an important aspect of job security - the overall regularity of employment-is not adequately addressed. Thus a useful indicator would measure the individual's pattern

${ }^{46}$ This approach has been used by, among others, the International Social Survey Program's Work Orientations modules, the General Social Survey in the United States, the British Workplace Employee Relations Survey, and the People's Security Surveys of the ILO's IFP/SES.

47 The "if you want to" clause of the question does not draw a clear distinction between purely personal circumstances and job-related reasons for being unable to continue. It may be difficult to specify this distinction, however, both because it is partly an issue of whether an employer will accommodate certain personal contingencies (e.g., maternity) and because work is not always as clearly separate from nonwork as it is for a regular employee. 
of employment (especially intermittency) during an interval longer than a reference week. Intermittency is an aspect of what is generally meant by "irregular employment," the other aspect being variability of earnings for a fixed amount of work. ${ }^{48}$ A brief summary of efforts in this direction can be found in Box 19a of Key Indicators of the Labour Market, 2001-2002.

Another possibility would be to develop indicators that measure legislative protection from dismissal. This could build on the work by Cazes and Nesporova $(2001)^{49}$ for OECD and Eastern Europe and Heckman and Page-Serra (2000) ${ }^{50}$ for Latin America. Such indicators are not suggested here because of the difficulties involved, especially the fact that such legislation is not always effectively applied in low-income countries, and especially for poor workers.

\subsection{Balancing work and family life}

\section{Background}

Reconciling work and family life has become a major public policy concern in many countries. It has always been a gender equity issue, since women throughout the world have main responsibility for family care and household work. Many factors have led to the mounting pressure on government and enterprises to address this aspect of decent work. Probably the most important pressure for "family-friendly" work has come from women because of their increasing participation in the paid labour market. Work-family issues, however, extend beyond caring for children as other family members may also require care. These issues, particularly those relating to childcare, are central to the achievement of the UN's Millennium Goal indicator concerning women in non-agricultural wage employment.

The ILO Workers with Family Responsibilities Convention, 1981 (No. 156) stipulates that national policies should aim to "enable persons with family responsibilities who are engaged or wish to engage in employment to exercise their right to do so without being subject to discrimination. Family responsibilities shall not, as such, constitute valid reason for termination of employment." Subsequently, but building upon earlier Conventions on the subject, the Maternity Protection Convention, 2000 (No. 183) specified the need for maternity benefits and for protecting women's jobs in the event of maternity.

Broadly speaking, there are three categories of family-friendly employment policies and issues: (1) job protection in the event a worker needs to be absent from work for an extended period for major family contingencies, such as maternity or child care; (2) monetary benefits in the event of major family contingencies; and (3) day-to-day accommodation of worker's need to integrate their work and family lives, such as flexible hours and adequate child care.

\footnotetext{
${ }^{48}$ Introducing the "casual labour" category into a labour force survey captures only one pattern of intermittency.

49 S. Cazes and A. Nesporova, "Job Insecurity in Transition Economies", International Labour Review, Vol.140, No. 3, 2001.

50 J. Heckman and C. Page-Serra, "The Cost of Job Security Evidence from Latin America Labour Markets", Economia, Fall 2000.
} 


\section{Indicators}

There is a paucity of available data outside of the OECD countries to measure the above three dimensions of balancing work and family life. Thus the suggested indicator list is short:

- employment rate for women with children under compulsory school age (ratio to the rate for all women aged 20-49) and

- excessive hours of work (discussed in Decent Hours).

The employment rate indicator can be derived from any labour force survey that collects information on household structure.

\section{Discussion}

The employment rate of women with children under compulsory school age measures the extent to which women exercise the option of having children and continuing to work. Its expression is clearest relative to the employment rate of all women aged 20 to 49 , which is why the suggested indicator is formulated as a ratio. The limited age range (20 to 49 years) used in the indicator mitigates the effect of international differences in school enrolment rates for younger women. Compulsory schooling begins at age 5,6 or 7 in every country or territory with data listed in the UNESCO Statistical Yearbook, 1999 (table 3.1), except Gibraltar. Some countries regularly publish employment rates for women with young children, but in many cases special tabulations will be needed.

Official labour force statistics classify women with young children as employed, whether they are at work or on maternity leave (either publicly mandated or provided as a private employment benefit) with the expectation of returning to the same employer. Therefore, the indicator combines the effects of two distinct paths for reconciling motherhood with work. Some women enjoy the protection of significant maternity or childcare leave, while others find childcare arrangements allowing them to return to work. Specifically then, a ratio of employment rates close to one indicates most women are continuing work, but does not indicate the means by which it accommodates women's need to work.

The employment rate indicator has an important shortcoming in that a higher ratio does not necessarily imply a better work-life balance. A high ratio could occur because economic circumstances force women back to work despite the unavailability of childcare of acceptable quality. Such a situation could not be characterised as decent work. A closely related point is that women with young children may return to work, but be able to do so only through self-employment or part-time work. ${ }^{51}$ Future development of indicators in this area should be sensitive to these issues. ${ }^{52}$

\footnotetext{
${ }^{51}$ In the development of this indicator, it would be useful to examine the self-employment and parttime employment rates for women with young children, as this may reveal important patterns.

${ }^{52}$ Ideally, the indicator should measure whether women have the option to return to work. Even with a very accommodating workplace, a woman may choose to remain out of the labour force to care for children herself. If many women make such a choice in such circumstances, this indicator would misleadingly suggest that workplaces were not accommodating to family needs.
} 
Table 14 shows the indicator and some related information. ${ }^{53}$ The contrast between the two labour market patterns is evident: Italy (with long mandated maternity leave but little formal child care) and the United States (with no mandated paid maternity leave but widespread formal child care). The ratio of employment rates is much lower in Australia, where there is neither long maternity leave nor widespread formal child care. It is difficult to know without in-depth study how to interpret the relatively low ratio of employment rates in Poland.

Table 14. Employment rate of women with children under 6 and related information

\begin{tabular}{|c|c|c|c|c|c|c|}
\hline Country & $\begin{array}{l}\text { Ratio of } \\
\text { employment } \\
\text { rates: } \\
(2) /(3)\end{array}$ & $\begin{array}{l}\text { Employment rate of } \\
\text { women with children } \\
\text { under } 6 \text { years }^{\mathrm{a}}\end{array}$ & $\begin{array}{c}\text { Employment rate } \\
\text { of all women, aged } \\
25-54\end{array}$ & $\begin{array}{l}\text { Percent of children } \\
\text { under } 3 \text { years in } \\
\text { formal child care } \\
\text { arrangements }\end{array}$ & $\begin{array}{c}\text { Duration of } \\
\text { paid maternity } \\
\text { leave (weeks) }\end{array}$ & $\begin{array}{c}\text { Maternity } \\
\text { benefits ( } \% \text { of } \\
\text { average } \\
\text { wages) }\end{array}$ \\
\hline & $(1)$ & (2) & (3) & (4) & (5) & (6) \\
\hline Australia & 0.67 & $45(2000)$ & $67.4(2000)$ & 15 (1999) & 0 & 0 \\
\hline Italy & 0.92 & 45.7 (1999) & 49.5 (1999) & 6 (1998) & 21.5 & 80 \\
\hline United States & 0.83 & 61.5 (1999) & 74.1 (1999) & 54 (1995) & 0 & 0 \\
\hline Poland & 0.70 & 47.6 (1999) & 67.6 (1999) & n.a. & 18 & 100 \\
\hline
\end{tabular}

Notes: a Mandatory school age is 6 years in Australia, Italy, and the United States, 7 years in Poland. b Refers to national legislation.

Source: OECD, Employment Outlook, 2001.

A particular statistical issue in countries with prolonged maternity/child care leave raises comparability problems in the present context. As mentioned earlier, these women are classified as employed, but many actually have weak or no attachment to their employer. In other words, these women are effectively out of the labour force. This is an especially important issue in transition economies because keeping women on extended parental/child-care unpaid leave has become a widespread practice in many transition countries. To improve both the qualitative and quantitative measure of people on parental/child-care leave, the $16^{\text {th }}$ International Conference of Labour Statisticians endorsed a set of guidelines recommended for use in national labour force surveys to test for a genuine employment attachment of persons on extended leave. ${ }^{54}$ A few countries have begun to implement these guidelines.

\section{Measuring public and private benefits provided to parents}

The balance between work and family life is particularly difficult for parents with young children. Without accommodation from employers and assistance from government, a good balance becomes nearly impossible. Social protection accorded to parents is a key foundation for establishing a work-life balance, not only because of the specific protections provided, but also because they create a climate in which

${ }^{53}$ The table uses the employment rate for women aged 25-54, rather than our preferred age range, because this age range is more readily available from published material for these countries. This may continue to be a difficulty in a more systematic application of the indicator, although substitution of the 25-54 age range is not likely to be a major problem.

54 See International Labour Office, Guidelines concerning treatment in employment and unemployment statistics of persons on extended absences from work, endorsed by the Sixteenth International Conference of Labour Statisticians (October 1998). Current International Recommendations on Labour Statistics. Second edition 2000. Geneva 2000, p. 88. 
accommodation becomes the expectation and the norm. The preferred indicators in this area would measure (i) the effective incidence and duration of job/employment protection for mothers and fathers and (ii) the incidence, duration and average level of monetary benefits for maternity and paternity. In each case, indicators should cover both public and private provisions.

This package of indicators is not feasible at present. However, ILO presently tracks, in paper files, a number of key components of such a set of indicators:

- statutory provisions for job/employment protection and monetary benefits for parents.

It is recommended that the ILO further develop this resource by coding the available information and putting it into an online database, so that it can be used in the development of the indicators mentioned above, as well as for other purposes. ${ }^{55}$ The additional steps required to construct satisfactory indicators require methodological development and will be difficult to implement. The two main difficulties are estimating private provision and effective coverage. The work by Gornick, Meyers and Ross (1997) on parental leave, childcare and scheduling of public education for industrialised countries provides useful guidance in this regard. ${ }^{56}$

A sense of the importance of private benefits can be gleaned from data for Australia, reported by Morehead, et. al. (1997). ${ }^{57}$ They report that, although private sector workers had no nationally mandated maternity leave (as of 1995), paid maternity leave was "available in 34 percent of workplaces, potentially covering 42 per cent of all full-time and part-time permanent female employees in workplaces with 20 or more employees."

The estimation of effective coverage for public provisions is a difficult and subtle process, even where raw data are generally available. The estimation must account for (at least) sectoral coverage, limits on size of covered establishments, restriction of benefits for short-tenure employees, and enforcement problems that suppress the take-up rate among eligible employees. Moreover, to prevent serious underestimation of coverage, the methodology would need to account for overlapping reasons for ineligibility. The gap between statutory and effective coverage is probably largest in developing countries, largely because of the size of the informal economy.

55 An example of this kind of database, encoding statutory provisions, was produced recently by IFP/SES for social security programmes.

56 J. Gornick, M. Meyers and K. Ross, "Supporting the employment of mothers: Policy variation across fourteen welfare states”, Journal of European Social Policy, Vol. 7, 1997.

57 Alison Morehead, et. al., Changes at Work: The 1995 Australian Workplace and Industrial Relations Survey, Addison Wesley Longman Australia Pty Limited, Melbourne, 1997. 


\section{Further work}

In light of the weakness of the indicators proposed in the area of Balancing Work and Family Life, it is clear that this is an area requiring considerable future effort. This is especially needed for developing countries; existing data would allow a far more satisfactory list of indicators for industrialized countries. The following areas are among those that would need to be developed and measured:

- the effective incidence and duration of job/employment protection for mothers and fathers, both publicly mandated and privately provided;

- the incidence, duration and average level of monetary benefits for maternity and paternity, both publicly mandated and privately provided;

- flexibility of work and accommodation of family needs (e.g., hours; sick child leave; bringing children to workplace; access to telephone for personal use);

- information on quality, availability, and affordability of formal child-care arrangements, including public subsidies and tax policies;

- workplace issues connected with aging populations

Most of the indicators above are mostly relevant for employees. Balancing work and family life is a often different for the self-employed. Future development of indicators in this area should try to capture these distinctions.

Expanding the list of indicators on Balancing Work and Family Life and measuring them for more countries will need to be a long-term effort and generally require special surveys and for new questions or modules added to existing surveys such as labour force surveys. Recent working conditions surveys carried out in several developing countries by ILO's Conditions of Work unit are a step in this direction.

\subsection{Fair treatment in employment}

\section{Background}

Fair treatment in employment is an intrinsic human expectation. At the international level, this has been expressed in terms of equality of opportunity in employment and occupation, and equal pay for work of equal value. The ILO Discrimination (Employment and Occupation) Convention, 1958 (No.111) defines discrimination as "any distinction, exclusion or preference made on the basis of race, colour, sex, religion, political opinion, national extraction or social origin which has the effect of nullifying or impairing equality of opportunity or treatment in employment or occupation". This list of characteristics could be extended to age, disability, disease or other grounds. The Equal Remuneration Convention, 1951 (No. 100) is concerned with discrimination in pay and equal remuneration for work of equal value. In addition to an absence of discrimination at work and in access to work, fair treatment means working without harassment or exposure to violence, some degree of autonomy, and fair handling of grievances and conflict. The latter is closely related to the existence or not of mechanisms at the workplace for social dialogue. 


\section{Indicators}

Suggested indicators for fair treatment, for the present, concentrate on differential treatment of men and women. In the future, efforts should be made to include indicators for other bases for discrimination such as race, ethnicity, religion and migrant status. The first two indicators discussed in this section measure equality of opportunity in employment. These indicators are based on an ILO database compiled by the Bureau of Statistics. The third and fourth indicators measure the extent to which women and men receive equal remuneration. Many other gender-related decent work indicators are provided by differentials between women and men for most other decent work indicators (see column 2 in Table 24 at the end of this paper).

- Occupational segregation by sex, (percent of non-agricultural employment in male-dominated and in female-dominated occupations and index of dissimilarity)

- Female share of employment in managerial and administrative occupations (ratio to female share of non-agricultural employment)

- Share of women in non-agricultural wage employment (see entry under Employment Opportunities),

- Female/male wage or earnings ratio, selected occupations (see entry under Adequate Earnings), and

- Female/male ratios or differences for other indicators (See entries under other headings)

\section{Discussion}

There are two main reasons for the focus on gender. First, gender discrimination is universal and has received by far the most attention, despite numerous other sources of discrimination. Second, data availability is much better for gender inequalities and discrimination than for other aspects of fair treatment such as autonomy, grievance settling procedures, and absence of harassment and violence.

\section{Occupational segregation by sex.}

Labour markets around the world are highly segmented based on gender. Approximately half of all workers in the world are in gender-dominated occupations where at least 80 percent of workers are of the same sex (Anker, 1998). ${ }^{58}$ This represents a major form of labour market rigidity that reduces employment opportunities, especially for women, and impairs economic efficiency. ${ }^{59}$ Occupational segregation is also associated with lower wage rates for women, as typical women's occupations tend to have lower pay, lower status and fewer possibilities for advancement as compared to typical male occupations. There is even evidence that increasing feminisation in an occupation negatively affects the wage rate in the occupation (Goldin, 2002). ${ }^{60}$

\footnotetext{
${ }^{58}$ Anker, R. Gender and Jobs, Sex Segregation of occupations of the world, ILO, Geneva, 1998.

${ }^{59}$ Male-dominated non-agricultural occupations are approximately seven times more common than female-dominated non-agricultural occupations (Anker, 1998).

${ }^{60}$ Goldin, C., A pollution theory of discrimination: male and female earnings in occupations and earnings, NBER, 2002, Working Paper 4985.
} 
The most common indicator of the level of occupational sex segregation in a country is the index of dissimilarity (ID). It is an inequality statistic whose value must be between 0 (no segregation) and 1 (complete segregation), although in practice national values are found to range from around .35 to around .75 (Anker, 1998). ID does not, however, measure discrimination per se, but only the tendency of labour markets to be segmented on the basis of gender. More direct measures of impairment in the voluntary choice of employment are indicators that measure the extent to which labour markets are separated into "male" and "female" occupations (that is, occupations whose gender composition is so unbalanced that most people would consider them to be either "male" or "female" occupations). For this reason, it is suggested to also include as decent work indicators the percent of the women/men in female-dominated, male-dominated and gender-dominated non-agricultural occupations. ${ }^{61}$ Occupational segregation indicators should be calculated for non-agricultural occupations, for both conceptual and practical reason. ${ }^{62}$

Table 15 provides data for the suggested occupational segregation indicators for three countries. India has the lowest level of occupational segregation according to the index of dissimilarity. A different picture emerges based on the percent of workers in genderdominated occupations, as India has a very high percent of non-agricultural employment in gender-dominated occupations (at 83 percent). India's non-agricultural labour force is so male-dominated that almost 90 percent of male non-agricultural workers are in a protected "male" occupation, whereas there are no female-dominated occupation among the specified 423 occupations. ${ }^{63}$ This picture emerges in large part because women comprise a small percent of the non-agricultural labour force in India.

${ }^{61}$ Gender-dominated occupations are defined as occupations where at least 80 percent of workers are either men or women (i.e., there are at least four males to every female or four females to every male). This definition represents a reasonable compromise between a more extreme definition (e.g., 90 percent, that would imply a sex ratio of at least 9 to 1), and a less extreme definition (e.g., 70 percent, that would imply a sex ratio of at least 2.33). The suggested definition has been used successfully in Anker (1998).

62 Agricultural employment is excluded for several reasons. On the practical side, agricultural employment, especially for women, is often inconsistently reported, and the very large size of agricultural employment in low-income countries would cause occupational segregation estimates to be determined by feminisation rates in agricultural occupations. On the conceptual side, the most important reason is that the determinants of occupational segregation are quite different for agricultural occupations (where family labour predominates) and non-agricultural occupations.

${ }^{63}$ Even with a much more detailed three-digit classification with 423 non-agricultural occupations, only three female-dominated occupations are found in India (professional nurse, professional midwife, and domestic ayahs and babysitters). 
Table 15: Occupational segregation by sex

\begin{tabular}{|c|c|c|c|c|c|}
\hline Country & Index of dissin & $\begin{array}{l}\% \text { female non- agric. } \\
\text { employment in a } \\
\text { female-dominated } \\
\text { occupation }\end{array}$ & $\begin{array}{l}\% \text { male non-agric } \\
\text { employment in a } \\
\text { male-dominated } \\
\text { occupation }\end{array}$ & $\begin{array}{c}\text { \% total non-agric } \\
\text { employment in a } \\
\text { gender- } \\
\text { dominated } \\
\text { occupation }\end{array}$ & $\begin{array}{l}\% \text { female in non- } \\
\text { agric. employment }\end{array}$ \\
\hline France ${ }^{c}$ & 0.56 & 22.0 & 50.7 & 42.1 & 42.6 \\
\hline Mauritius ${ }^{c}$ & 0.59 & 14.0 & 68.2 & 54.7 & 31.1 \\
\hline India b & 0.45 & 0.0 & 87.3 & 83.3 & 12.1 \\
\hline
\end{tabular}

Notes: Values adjusted to two-digit classification with similar level of disaggregation. Gender-dominated occupations are defined as occupations where at least 80 percent of workers are male or female.

b 1981 c 1990

Source: Anker, R. Gender and Jobs: Sex segregation of occupations in the world, ILO, Geneva, 1998

One characteristic of occupational segregation indicators requiring discussion (and treatment) is their sensitivity to the level of disaggregation in the occupational classification on which they are based (see Anker, 1998). The values reported in Table 15 were adjusted to take this into account. This sensitivity can be illustrated by unpublished results for France (shown in Figure 2) where ID was calculated for different classifications $(5,28,119$ and 428 non-agricultural occupations) and years $(1982,1990,1999)$. In 1999, ID rose from .385 to.514, .554 and .580 as the level of disaggregation in the occupational classification increased. $^{64}$ Just as important, trends over time based on the 5 and 28 occupation classifications give a false picture for France. Between 1982, 1990 and 1999, ID rose according to estimates based on data with 5 and 28 non-agricultural occupations, whereas ID fell according to estimates based on data with 119 and 428 non-agricultural occupations. At least two-digit data are required with generally more than 50 or so nonagricultural occupations for occupation segregation indicators for ID values to be reasonably robust with regard to further disaggregation in the classification (Anker, 1998).

To support the compilation of this indicator, the SEGREGAT database maintained by the ILO Bureau of Statistics should be improved in terms of country coverage and updated at regular intervals.

\footnotetext{
${ }^{64}$ As shown in Anker (1998) based on data for a number of countries, the relationship between ID and number of occupations classified resembles a log function.
} 


\section{Figure 2. Occupational segregation by sex (ID) by level of disaggregation in occupational classification, France 1982- 1999}

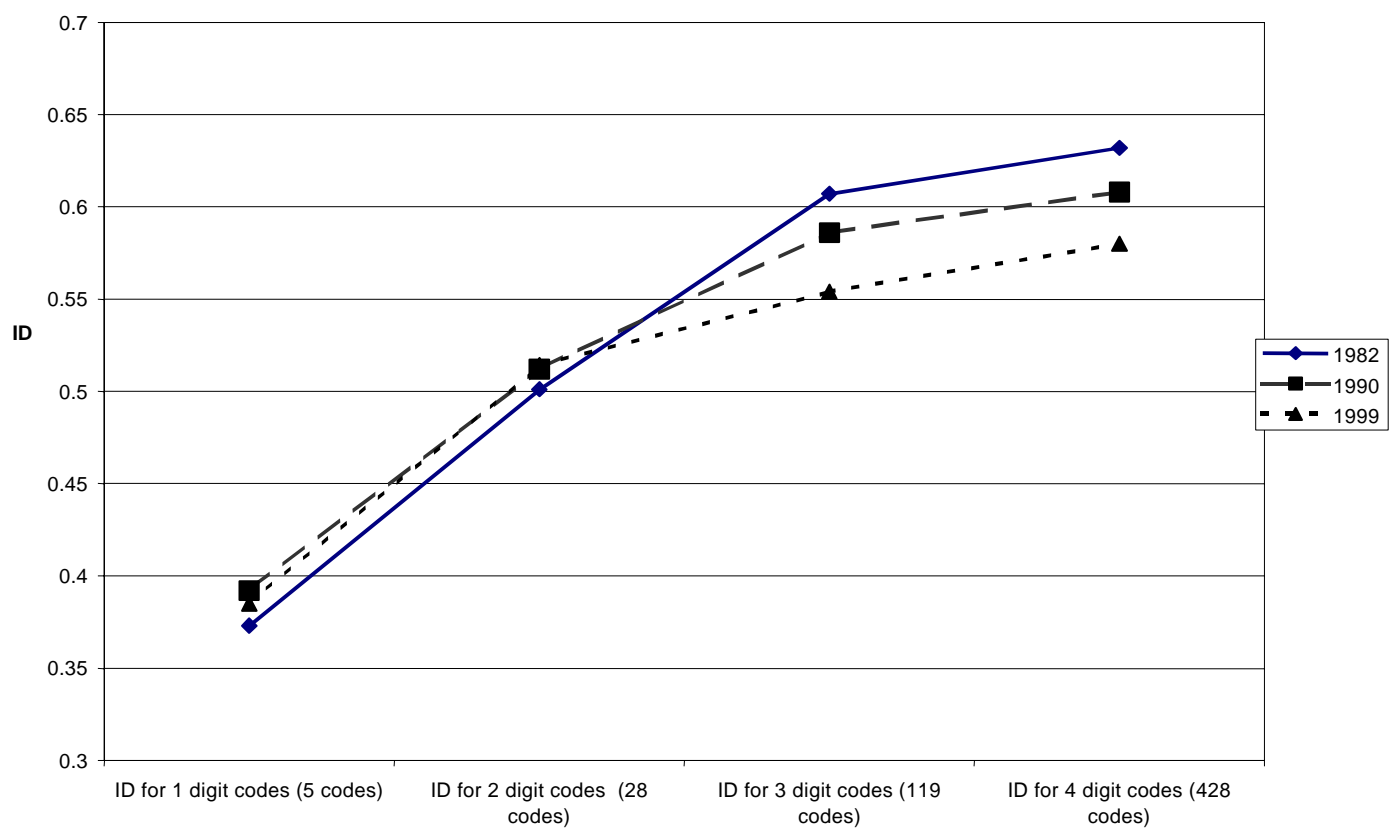

Source: ILO SEGREGAT database, unpublished official data.

Female share of employment in managerial and administrative occupations.

The distribution of women and men across levels of responsibility is an important measure of equal treatment in employment. One indicator of this is the extent to which women are in positions of authority and decision-making, such as managers and administrative workers. ${ }^{65}$ It is suggested that this indicator also be reported relative to women's share of non-agricultural employment to take into account differences across countries in women's overall share of non-agricultural employment (since one would naturally expect to find low female shares in countries with low female shares of overall employment). This would be a relative indicator where a value above 1 would indicate that women are over-represented in decision-making positions compared to their average overall participation in non-agricultural employment, and a value below one would indicate relative under-representation.

Data are available in the ILO Yearbook of Labour Statistics for a substantial number of countries. Table 14 provides values for three countries. Although percent female is similar in Spain and Tunisia at around 9 percent, the relative rate is almost twice as high in Tunisia. This occurs because women's share of non-agricultural employment is much

${ }^{65}$ It might seem reasonable to also include professional and high-level technical occupations as these are also high-level jobs. This does not turn out to be a good idea in practice, because most women professionals and high technical workers are in only two occupations, teachers and nurses (Anker,1998). 
lower in Tunisia as compared to Spain. Also worth noting is the relatively large size of managerial and administrative occupations in the United States (13 percent). This is partly attributable to use of a broader definition for this group in the United States. One aspect of non-comparability that will need to be addressed is that national estimates in the ILO Yearbook of Labour Statistics are provided for two different occupational classifications, ISCO-68 and ISCO-88. ISCO-88 is more inclusive in that it includes additional supervisory and managerial occupations that appear under sales, services, and agriculture in ISCO-68. Further investigation of the correspondence in practice between values based on ISC0-68 and ISCO-88 is required in order to improve cross-country comparability for this indicator.

Table 16. Women in managerial and administrative occupations

\begin{tabular}{lccc}
\hline Country & \% female & $\begin{array}{c}\text { \% female relative to \% female in } \\
\text { non-agric. labour force }\end{array}$ & $\begin{array}{c}\text { \% of non-agric. employment in } \\
\text { managerial and admin. } \\
\text { occupations }\end{array}$ \\
\hline USA a & 40.7 & 0.88 & 12.8 \\
Spain b & 9.2 & 0.28 & 2.1 \\
Tunisia & 9.4 & 0.48 & 2.1 \\
& & & \\
Notes: ${ }^{2}$ 1991 ${ }^{\circ}$ 1990 c 1989 &
\end{tabular}

Female/male hourly wage earnings ratio, selected occupations.

The principle of equal pay for work of equal value is well established and recognized. It is enshrined in ILO Equal Remuneration Convention (No. 100). However the notion of equal work of equal value tends to be lost in aggregate measures of earnings differentials between men and women especially due to their concentration in different occupations, and economic sectors, along with differences in the number of hours worked. The ratio of women's to men's hourly wage in narrowly defined occupations should provide a reasonable approximation, depending on the extent to which the occupations chosen are heterogeneous. Discussion and Table 8 on this can be found in the section on Adequate Earnings and Productive Work.

A possible complementary indicator would be the ratio of female and male average or median hourly wage rates for all non-agricultural occupations. Although less precise than ratios of female/male pay rates for the selected occupations, this complementary indicator does provide an overall measure of gender pay inequality and it could be available in countries for which data on hourly earnings by sex for selected occupations are not readily available.

\section{Female/male ratios or differences for other indicators.}

To the extent permitted by the available data, all decent work indicators should be disaggregated by sex. A useful measure of the relative position of women is the female/male ratio for some of the more current indicators available for women and men separately. An example is given below for the unemployment rate. 
Table 17 Ratio of female to male unemployment rate

\begin{tabular}{lcc}
\hline Country (2000) & Female/male ratio & Total unemployment rate \\
\hline Canada & 0.97 & 6.8 \\
Korea, Rep.of & 0.72 & 4.1
\end{tabular}

Source: ILO Yearbook of Labour Statistics, 2001.

\section{Further work}

Segregation and discrimination are obviously not limited to gender. There are many other grounds for differentiated treatment and discrimination in the labour market, including race, ethnicity, religion and social origin. In an era marked by increasing globalisation, national origin and migrant status are increasingly important characteristics giving rise to differential treatment. Thus one area for future work would be the development of indicators to address:

- major forms of discrimination on the basis of religion, ethnicity, national origin, etc.

As mentioned earlier, such indicators require countries to specify the main targets of discrimination in their country. Although which groups are disadvantaged and discriminated against differs across countries, as do the specific forms of discrimination (e.g., pay, hiring, promotion, contract status etc. ${ }^{66}$, most countries have disadvantages groups. ILO should encourage countries to report decent work data by major social group, even if countries are reluctant to report such data for political reasons.

Other non-gender specific breaches of the principle of fair treatment also merit greater attention. In particular, future data collection efforts through labour force surveys and decent work surveys are needed before indicators on harassment, including sexual harassment, violence, autonomy, and grievance-settling at the workplace become available for a significant number of countries.

- harassment

- autonomy

${ }^{66}$ For example, People's Security Survey data for Bangladesh (specifically, Dhaka) from ILO's Social-Economic Security Programme show widespread support for discrimination in hiring, but little support for discrimination in pay. This pattern applies to preferences given on the basis of sex, age, and marital status. See Levison, D., J. Ritter, R. Stock, and R. Anker, "Normative Judgements from Four Continents about the Distribution of Income and Job Opportunities," manuscript, ILO, July 2002. 


\subsection{Safe work}

\section{Background}

The ILO estimates that globally over 2 million workers die annually from work related fatal injuries and diseases. On average, every day of the year, some 5,400 workrelated deaths occur (Takala, 2002). ${ }^{67}$ The aggregate cost of occupational injuries and diseases is estimated between 1 and 6 per cent of GDP, with a distribution of the costs between society, enterprises and workers leaning heavily on the latter (Dorman, 2000). ${ }^{68}$

In general terms, safety and health at work is about conditions that preserve and promote the physical and psychological integrity of the worker. The Occupational Safety and Health Convention, 1981 (No.155) calls for a national policy to "prevent accidents and injury to health arising out of, linked with or occurring in the course of work by minimising so far as is reasonably practicable the causes of hazards inherent in the working environment". The Employment Injury Benefit Convention, 1964 (No.121) establishes the principle of employer responsibility for insuring employees for occupational injury. The labour inspectorate is an important means of enforcement of the principles of national legislation and regulation (Labour Inspection Convention, 1947 (No.81)).

A close relationship can be established between objective conditions of safety and health at work, perceptions of such conditions, and the performance of persons at work. The nature of work as a coordinated set of activities carried out in specified conditions means that all work is exposed to some degree of risk. Risk comes in many formsrepetitive tasks, long hours, exposure to harmful substances, noise, psychological pressure, physical aggression and much more. The degree of risk varies according to occupations, economic activity, type of establishment, characteristics of workers, and so forth. Preventive measures can take many forms: engineering controls, elimination of hazards, substitution of less hazardous substances or processes, safety and health education, protective equipment, careful design of workflow, and limiting the participation of vulnerable groups (e.g., young workers).

\section{Indicators}

The suggested indicators measure or proxy for: (i) level of workplace safety in terms of outcome; (ii) State effort to enforce safe working conditions; (iii) insurance coverage in the event of occupational injury; and (iv) long hours of work, one aspect of unsafe working conditions. The first three indicators will require considerable effort to establish data sets with reasonable cross-country comparability for a substantial number of countries.

- Fatal injury rate (per 100,000 employees)

- Labour inspectors (inspectors per 100,000 employees and per 100,000 covered employees)

\footnotetext{
${ }^{67}$ Takala, J Decent Work - Safe Work, Introductory report to the XVIth World Congress on Safety and Health at Work, Vienna, 27 May 2002.

${ }^{68}$ Dorman, P. The Economics of Safety, Health, and Well-Being at Work: An Overview, ILO, Geneva, May 2000.
} 
- Occupational injury insurance coverage (percent of employees covered by insurance)

- Excessive hours of work (see entry under Decent hours)

\section{Discussion}

Fatal injuries

Currently, the ILO Yearbook of Labour Statistics publishes annual data based on administrative sources, on fatal and non-fatal occupational injuries and days lost as a result of such injuries. Varying reporting formats hamper the comparability of the data. So does the completeness of reporting, and the partial coverage of certain sectors and small enterprises.

Fatal injuries is suggested as a safe work indicator rather than non fatal injuries, because it's reporting is believed to be more complete and have fewer definitional problems compared to non-fatal injuries. There are none the less many difficulties. The period during which death will be attributed to a specific accident commonly varies between 6 months to one year, thereby excluding deaths linked to occupational diseases with a long latency period (such as asbestosis, and many work-related cancers). Injuries can be reported through an administrative notification system (such as labour inspection) or through an insurance scheme. In either case reporting is limited to the workers covered by the system. As shown in the table below, there are large variations of reported fatal injury rates across economic sectors, and consequently the industrial structure can have a major affect on the observed rate for a country (though it is important to bear in mind that this is part of what the measurement is intended to capture). The use of wage employment as the denominator helps improve cross-country comparability (although it fails to capture the situation for all workers - an important shortcoming), since underreporting is likely to be greater for self-employed workers.

Table 18: Fatal injury rate per 100,000 wage workers

\begin{tabular}{lccc}
\hline Country & Total & Construction & Transport \\
\hline Egypt (1999) & 8 & 18 & 8 \\
Finland (1998) & 3.2 & 9.8 & 10.9 \\
Panama (1998) & 14 & 52 & 28
\end{tabular}

Source: ILO Yearbook of Labour Statistics.

Future efforts could also be directed toward developing indicators of fatal injuries by age and contractual condition, as there is substantial evidence at the international level that persons on temporary and short-term contracts are associated with measurably worse occupational safety and health outcomes (Bohle, Quinlan and Mayhew, 2001). ${ }^{69}$

${ }^{69}$ Bohle, P., Quinlan, M. \& Mayhew, C. "The health and safety effects of job insecurity: An evaluation of the evidence", in The Economic and Labour Relations Review, Vol. 12, No. 1, June 2001 . 


\section{Labour inspection}

The number of labour inspectors is a good proxy of the state's capacity to enforce safe work principles, laws and regulations, and hence a good proxy for prevention efforts. Data are not currently published for this indicator, but administrative sources available to the ILO could be compiled.

In many countries, national legislation determines the scope of labour inspection coverage, in terms of economic sector. This information could be utilised to estimate the sectoral (and employment) coverage of labour inspection. By combining information on the number of labour inspectors and the economic activities covered by those inspectors, it would be possible to calculate the number of labour inspectors per 100,000 covered workers as an indication of the intensity of inspection effort where it occurs. Combined with the coverage rate for the working population, it would be possible to distinguish between countries with widespread coverage at modest intensity and countries with narrower coverage at higher intensity. Since determining covered employment may prove difficult because it requires knowledge of the details of coverage rules along with data on employment by industrial sector at a sufficiently disaggregated level to be compatible with the detail specified the national legislation, the indicator of intensity of labour inspection in covered sectors will require further development.

\section{Occupational injury insurance coverage}

The ILO has last published data on insurance coverage of wage employees for occupational injury in the World Labour Report, 2000 for the year 1996 for 36 countries. Some examples are given in the table below. This database has since been discontinued. Alternative ways of reinitiating this source of information are being considered by the ILO Programme IFP/SAFEWORK. Future efforts could consider reporting by economic sector and for wage employees.

Table 19. Percentage of labour force protected by employment injury insurance

\begin{tabular}{lc}
\hline Country & Percentage \\
\hline Chile & 26.5 \\
Panama & 36.6 \\
Saudi Arabia & 33.2 \\
& \\
Notes: For 1996 & \\
Source: ILO Yearbook of Labour statistics and national sources. & \\
\hline
\end{tabular}

\section{Further work}

A priority for future work is to thoroughly assess and possibly improve the measurement of occupational injuries and disease, as well as the associated lost work time. Current reporting on the actual incidence of occupational injury and disease is unsatisfactory in many countries. Although the extent of underreporting is not known to any degree of precision, it is believed to be very large in many countries. It remains to be determined if injuries data is so flawed that the considerable effort required to continue to collect and report such data is worth the effort. The discussion on the recording and 
notification of occupational accidents and diseases at the June 2002 International Labour Conference provides a basis for future guidance and practice. ${ }^{70}$

Many other areas of safe work are neglected by the list of suggested indicators for reasons of practicality and current data availability. These include sick leave entitlement, incidence of occupational diseases, a broader range of physical and mental problems associated with work (e.g., stress), entitlement to breaks, existence of adequate toilet facilities, and various hazards.

Finally, given the large holes in the statistical picture of safe work, it is worth mentioning that various aspects of safe work are amenable to measurement by survey methods. Specifically, the injury rate, sick leave entitlement, entitlement to breaks, availability of toilet facilities, and similar items could be directly estimated using survey questions. ${ }^{71}$ IFP/SAFEWORK and Bureau of Statistics in ILO have experimented with the collection of injury data using household surveys. Psychologists have also developed reliable methodologies for measuring stress using surveys (though it is difficult to clearly attribute stress to work only). Other aspects of safe work appear less tractable using surveys. In particular, comprehensive measurement of hazards is difficult due to the number of potential hazards. Thus, while it is fairly straightforward to measure exposure to, say, pesticides, a comprehensive list of such specific hazards would be overwhelmingly long. ${ }^{72}$ Grouping hazards into categories such as "dangerous chemicals" reduces the list, but at the expense of introducing ambiguity, and therefore, subjectivity.

\subsection{Social protection}

\section{Background}

Adequate social protection is a defining feature of decent work around the world. Exposure to risks and the type and level of protection available differ greatly among societies, even though the need for protection from life risks is felt by persons in all countries. Most countries have introduced some forms of social protection against life contingencies (such as ill health, old-age, unemployment, and disability) as well as for poverty. Yet the ILO estimates that only some 20 per cent of the world's labour force has access to adequate social protection. ${ }^{73}$

70 See in particular Parts I to III of the Protocol to the Occupational Safety and Health Convention, 1981, adopted by the International Labour Conference, 90 ${ }^{\text {th }}$ session, ILO, Geneva, 2002.

71 Such surveys must be realistic about the statistical properties of estimates for low-probability events such as workplace injuries. For example, random samples of more than 3700 are required to determine that a "large" change from a 5 percent injury rate to a 4 percent rate is statistically significant at the 95 percent confidence level. Although an even larger sample would be required to make a statistically meaningful comparison between 50 and 49 percent rates, such a reduction would not be regarded as "large" in a practical sense by users of the statistics. For similar reasons, comparisons of injury rates between all but the largest groups is problematic. Estimation of the incidence of low-probability events is also especially sensitive to none-sampling errors such as misreporting.

72 Again, it should be recognized that exposures to narrowly defined hazards are generally lowprobability events, presenting the statistical difficulties mentioned in the previous footnote.

${ }^{73}$ ILO, Report of the Director General to the International Labour Conference, June 2001. 
The need for social protection is recognized by the ILO Constitution. The Resolution on Social Security adopted by the International Labour Conference in 2001 defines social security as a basic human right and a means to foster social cohesion, human dignity and social justice. The Social Security (Minimum Standards) Convention, 1952 (No.102) established nine classes of benefits: medical care, sickness benefit, unemployment benefit, old-age benefit, employment injury benefit, family benefit, maternity benefit, invalidity benefit and survivors' benefit. An important consideration is the extent to which these and other forms of support are available to the poor.

Social security systems around the world display a variety of institutional structures. They are public, private and mixed; compulsory and voluntary; universal and targeted. Many of these arrangements are employment based. Despite this institutional diversity, the common goal of social security is to provide basic protection against the financial consequences of basic life contingencies for workers and their families. Measuring social protection should aim to capture its three main dimensions for each contingency covered, namely: population coverage (in terms of access, entitlement or contributions), benefit levels (in relative terms), and expenditures.

\section{Indicators}

The decent work indicators suggested for social protection stress effective coverage and actual benefit levels for workers and the population, rather than describing statutory and institutional arrangements which may not have wide coverage in practice. The only indicator for which data are currently available and maintained for a substantial number of countries is total public social security expenditure. Discussion and preliminary efforts are, however, underway in ILO (partly in collaboration with ISSA) to possibly rectify this situation at least for the main contingencies of medical care, sickness, old age, and unemployment. The outcome of this effort will help determine if data will become available for a substantial number of countries for at least the following set of social security decent work indicators.

- Public social security expenditure (percent of GDP, separately for total, health services, and old-age pensions)

- Public expenditure on needs-based cash income support (percent of GDP)

- Beneficiaries of cash income support (percent of poor)

- Share of population over 65 years benefiting from a pension

- Share of economically active population contributing to a pension fund

- Average monthly pension (percent of median/minimum earnings), and

- Occupational injury insurance coverage (see entry under Safe Work)

\section{Discussion}

Total public social security expenditure is a synthetic indicator which measures the overall public redistributive effort. It is a useful indicator for comparative purposes. Data are available from the IMF Government Finance Statistics Yearbook as well as from an ILO database further refining the government expenditure categories used by the IMF. A complementary indicator derived from the same sources is the share of public social security expenditure as a percentage of total government expenditure. By way of illustration, the following table provides data for three countries. As expected, public 
social security expenditure (as a percent of GDP and as a percent of total government expenditure) is positively related to per capita income.

Table 20. Public social security expenditure

\begin{tabular}{lccc}
\hline & Japan & Indonesia & Mexico \\
\hline Public expenditure on health care as \% of GDP & 5.7 & 0.4 & 2.0 \\
Public expenditure for pensions as \% of GDP & 7.1 & na & 4.9 \\
Total public social security expenditure as \% of GDP & 15 & 3.9 & 8.2 \\
Social security expenditure as \% of total government expenditure & 38 & na & 42
\end{tabular}

Notes: For 1998-99

Source: ILO social protection database

\section{Old-age pensions}

Contributing to an old-age pension fund (whatever its institutional form) whilst of active age, and benefiting from a pension during old age, are important forms of security and protection against destitution and poverty as well as dimensions of decent work. Data for these old-age pension indicators were previously available for a wide range of countries in the ILO International Inquiry into the Cost of Social Security until 1997, when this series was discontinued. ILO could develop a database (partly in collaboration with ISSA) on the selected indicators, perhaps as a first step to compiling a more complete database with additional indicators and other life contingencies. A supplementary source of information, especially in the future could be labour force surveys that inquire about contributions to different forms of social security.

\section{Public cash income support for the poor}

An important dimension of social security is assistance to population groups in poverty, for example those: with income from work below some agreed national threshold, temporarily without employment, unable to work, or above the usual retirement age and without pension benefit. Entitlements to cash benefits from the State as the guarantor of last resort of a minimum livelihood for its citizens come in various forms: old-age pensions, survivor's benefit, invalidity benefit, family allowances, child benefit, social assistance, unemployment benefits. Not all of such benefits are granted in cash. Many are in-kind in the form of meals, supplementary diets, foodstuffs, and the like. Given the variety of means under which in-kind assistance is supplied, and the difficulty in measuring these in practice a convenient way of measuring the total social assistance effort for the poor is to consider only cash benefits.

Cash benefits to the poor are usually non-contributory, often means-tested, and directed at low-income groups. They represent an important means to combat destitution and poverty and to foster social cohesion. A preliminary database and methodology on cash income benefits for the poor has been established in the ILO for a limited number of (non-OECD) countries. ${ }^{74}$ This effort needs to be evaluated and expanded on a trial basis in order to ascertain its feasibility to expanding country coverage using available administrative data.

\footnotetext{
${ }^{74}$ Van Ginneken, W, ILO tax-based social benefits database for 12 countries, 2001.
} 


\section{Further work}

Access to, or coverage of, health services is a relatively straightforward concept, yet difficult to measure. In practice, effective access includes several dimensions such as physical proximity, entitlement, and level and quality of the care available. Proxy indicators measuring the outcome of health services as well as the inputs in terms of expenditure are widely used. From a protection perspective, the important element is whether an employed person contributes to a health insurance scheme and therefore gains entitlement to medical services. A possible indicator could be percent of the population (or employed population, or wage earners) contributing to a health insurance scheme (whether statutory or voluntary, public or private). Although some data are readily available for this indicator, considerably more data could be derived from labour force surveys if questions on contributions to social security are included. Countries in which health care is a universal benefit would need to be treated differently.

\subsection{Social dialogue and workplace relations}

\section{Background}

An important dimension of decent work is the extent to which workers can express themselves on work-related matters and participate in defining their working conditions. This can be channelled through collectively chosen representatives or involve direct interaction between the worker and employer. The ability of workers to organise freely to defend their interests collectively in negotiations with the employer is a pivotal element of democracy at the workplace and the effectiveness of social dialogue. In a more general sense, social dialogue is any type of negotiation, consultation or exchange of information between, or among, representatives of governments, employers and workers, on issues of common interest relating directly to work and related economic and social policies.

Several key ILO conventions address conditions for and exercise of social dialogue, in particular Convention No. 87 (1948) on Freedom of Association and Protection of the Right to Organise and Convention No. 98 (1949) on the Right to Organise and Collective Bargaining. Convention No. 87 establishes the right of employers and workers and their respective organisations to "establish and join organisations of their own choosing without previous authorisation". This right consists of two elements: first, whether the conditions, particularly legal conditions, are such that the right can be exercised and second, the extent to which this right is exercised in practice. Since these rights should be exercised voluntarily according to ILO Conventions, the existence and exercise of these rights need not necessarily coincide.

\section{Indicators}

The following three social dialogue indicators have been selected based in large part on data availability and feasibility. Other important social dialogue indicators require further conceptual and measurement development, such as the right and freedom to organise and bargain collectively; the institutional pattern of social dialogue, specifically the extent to which social dialogue and collective bargaining are centralised and coordinated; the participation of workers in decision-making at the workplace and in workers' organisations; and direct employer-employee relations.

- Union density rate,

- Collective wage bargaining coverage rate, and 
- Strikes and lockouts (per 1000 employees)

\section{Discussion}

Union density rate

The World Labour Report (ILO, 2000) published data on union density rate for a substantial number of countries. The most recent year, however, is 1995. A systematic effort is required to establish and regularly update within ILO a database on trade union membership. For this, a standardized definition of trade union membership is necessary; one possibility is: dues paying workers. The preferred denominator for calculating the union density rate is total wage employment. The trade union density rate is used here as a proxy for trade union representation and strength. Since union membership varies greatly across sectors of the economy, it would be useful to report union density rate by industrial sector whenever this is possible.

Union membership should ideally be disaggregated by sex so that it would be possible to estimate percent female among union members. It would also be useful to know percentage of union leaders that are female. Since only a limited number of countries maintain union membership records by sex, these gender indicators are for future development.

- Percent female among union members

- Percent female among union leaders

\section{Collective wage bargaining coverage rate.}

The World Labour Report (ILO, 2000) also compiled national data on workers covered by a collective bargaining agreement as a percentage of total wage employment. The wage being a central element of the terms and conditions of employment, the number of workers covered by a collectively negotiated wage agreement provides a good indicator of the degree of participation and the relative strength of workers' organisations. This would be a direct application of the ILO Right to Organize and Collective Bargaining Convention, 1949 (No. 98), that establishes the principle of the "full development and utilisation of machinery for voluntary negotiation between employers or employers' organizations and workers' organizations, with a view to the regulation of terms and conditions of employment by means of collective agreements".

Table 21 provides data for three countries on the above two indicators. These data illustrate that trade union density rates and collective bargaining coverage rates do not always move together. In fact, the institutional arrangements under which social dialogue and collective bargaining take place often shape outcomes beyond what the relative strength of the parties (as assessed by membership rates) would suggest.

Table 21. Union density rate and collective bargaining coverage rate (percent of wage workers)

\begin{tabular}{lcc}
\hline Country & Trade union density rate & Collective bargaining coverage rate \\
\hline Panama & 20.1 & 16 \\
Thailand & 4.2 & 26.7 \\
United Kingdom & 32.9 & 25.6
\end{tabular}


One characteristic that affects the effectiveness of collective bargaining is the degree to which it is centralized and coordinated. An extensive research literature is concerned with the consequences for economic performance (growth, unemployment, income distribution) of wage-setting arrangements, in particular whether these are centralized or decentralized, coordinated or not directly by employers and workers and the state, or indirectly effective through pattern setting. Various examples of methodologies for measuring modes of wage setting are suggested in Kentworthy and Kittel (2002) ${ }^{75}$ using a scoring system based on information provided by country-based experts. While such a system and set of indicators could be developed in the future, they are not recommended here for future work because of the difficulty and subjective judgements required, as well as the many other aspects of social dialogue needing to be measured.

\section{Strikes and lockouts.}

One measure of the failure of social dialogue is the recourse to strike. At the same time in certain circumstances, the absence of strike action could indicate the absence of the right to strike and weak social dialogue.

The ILO Yearbook on Labour Statistics reports annual strikes and lockouts data. Although not all countries report strike action in exactly the same way (with variations according to sectors and establishment sizes covered, whether strikes are local or national, and whether "political" strikes are excluded), nevertheless the data cover a substantial number of countries; and these data are used by other international organisations (such as the OECD). Future efforts should be directed to improving cross-national comparability. The following table provides data for three selected countries for two different time periods. Notice how much rates vary between time periods, due to a large national strike in one time period only.

Table 22. Days lost through industrial action per 1,000 wage employees (3-year averages)

\begin{tabular}{lcc}
\hline Country & $1992-94$ & $1998-2000$ \\
\hline Panama & 3.2 & 1141.4 \\
Thailand & 27.1 & 16.6 \\
United Kingdom & 21.7 & 14.1 \\
& & \\
Source: ILO Yearbook on Labour Statistics, 2001. & & \\
\hline
\end{tabular}

\section{Future work}

Future work on statistical indicators of social dialogue could take a number of directions, thereby moving beyond the above three selected indicators that mainly measure institutions and institutional arrangements and strength. The following areas are listed as potential social dialogue indicators for future development (including those noted earlier concerned with percent female among union members and union officers). Substantial effort, however, would be required to define approaches to measurement, set priorities, and collect national data before they can be included as ILO core decent work indicators.

- Participation in workplace decision-making

- Employer-employee relations

75 Kentworthy, L. and Kittel, B., Indicators of social dialogue: concepts and measurement, Unpublished. ILO, Geneva, 2002. 
- Percent female among union members

- Percent female among union officers

- Union member participation in union elections and decision-making

- Union participation in public policy making

Notice that a statistical indicator is not listed above to measure legal and/or practical restrictions to freedom of association in countries and right to bargain collectively. The main reason why a quantitative indicator is not suggested to measure restrictions on freedom of association and rights to bargain collectively (perhaps with ordinal values as simple as: (1) no or virtually no restrictions; (2) some restrictions; and (3) major restrictions) is that such an indicator would be very difficult to develop and maintain. It would require an enormous effort by the ILO to develop and maintain a systematic information system for all countries, a transparent scoring system that would be acceptable to the tripartite constituents, and a political will in the ILO to report and defend resulting national values. It is one thing to use national values developed in Kucera $(2001)^{76}$ for multi-variant cross-country empirical analysis relating core labour rights to labour costs and foreign direct investment.. It is another matter to report national values. If on the other hand, ILO would put in the requisite effort and resources as well as muster the political will to defend the results against inevitable national criticisms, a quantitative indicator of restrictions on freedom of association and right to bargain collectively would be a possibility and would be welcomed. It is interesting to note that efforts are underway on this in the United States, where based on a preliminary investigation by the National Academies of Science, the U.S. Department of Labour plans to fund a large project on reliable and sustainable approaches to gathering credible information and data on the extent to which countries effectively promote ILO's core labour standards as embodied in the ILO Declaration of Fundamental Principles and Rights of Work that includes freedom of association and the right to bargain collectively.

An alternative approach worth considering would be to develop and maintain information sheets for each country in the world on restrictions on freedom of association and the right to bargain collectively - - without going on to measure and report a quantitative statistical indicator. This could include information on the application of relevant ILO conventions in reports of the ILO Committee of Experts on the Application of Conventions and Recommendations reviewing the application of ratified Conventions, activities of the ILO Committee on Freedom of Association, and reports prepared under the follow-up to the ILO Declaration on Fundamental Principles and Rights at Work for countries not having ratified the relevant Conventions. Reports on restrictions from constituents, media or others could also be solicited and used.

- Information sheets (and possibly indicator) on restrictions on freedom of association and right to bargain collectively.

76 Kucera, D., The effect of core workers' rights on labour costs and foreign direct investment: Evaluating the "conventional wisdom”, ILO Institute of Labour Studies, Paper No. 130. 2001. 


\subsection{Economic and social context of decent work}

\section{Background}

Up to this point, the concern has been with measurement of decent work. It is important to also consider the economic and social context within which decent work occurs. Three aspects of the context are considered here: (i) socio-economic context which may condition or affect the sustainability of decent work; (ii) socio-economic performance that the achievement of decent work might affect; (iii) aspects of employment composition that are needed to measure some decent work indicators.

\section{Indicators}

With the exception of the informal economy indicator, only indicators that are available in existing international databases for a wide range of countries are included here. The following indicators are felt to be particularly useful:

- Output per employed person (PPP level),

- Growth of output per employed person (total and manufacturing),

- Inflation (consumer prices where available),

- Education of adult population (adult literacy rate, adult secondary school graduation rate),

- Composition of employment by economic sector (agriculture, industry, services)

- Income inequality (ratio of top 10 percent to bottom 10 percent, income or consumption), and

- Poverty (percent of population subsisting on less than $\$ 1 /$ day or less than $\$ 2 /$ day).

- Informal economy employment (percent of non-agricultural or urban employment).

\section{Discussion}

\section{Output and growth per employed person}

Labour productivity measured as output (GDP) per employed person summarises, albeit imperfectly, the overall ability of an economy to generate value from labour inputs. Its growth rate can be thought of as measuring economic growth abstracting from the growth of the labour force (labour input). ${ }^{77}$ Low or declining labour productivity is a signal of broad economic difficulties. In a cross-section of economies, much of the variation in labour productivity reflects different levels of capital accumulation and is therefore closely correlated with the level of economic development. Other influences on

\footnotetext{
77 "Labour productivity" generally means output per hour worked. When appropriate measurements of the number of hours are not available (as occurs for many countries), output per employed person is used since it tracks changes in output per hour as long as average hours does not change significantly. Average hours per employee varies significantly among countries, and this fact is important to interpreting output per employed person across countries.
} 
labour productivity are also important. These include human capital, the technical efficiency of production methods that transform inputs into economic output, and features of the political economy of the country that enhance or inhibit the efficiency of the economy. ${ }^{78}$

In an economy with low or stagnant labour productivity, policymakers will, at least in the short run, face a less attractive menu of choices vis-à-vis decent work and other economic goals. It should not, however, be presumed that providing decent work is necessarily antithetical to economic growth. On the contrary, research in a number of areas has suggested various microeconomic channels for positive feedback between aspects of decent work and economic success. ${ }^{79}$ The nature of the macroeconomic feedback depends critically on the details of implementation of labour market and social policies for decent work. There is, potentially, feedback in the opposite direction as well: Sound decent work policies can be subverted by unsound policies in broader social or economic arenas. And, establishing the link between decent work and economic growth and performance in different social and economic settings is an important empirical issue that needs to be investigated.

International comparisons of labour productivity require GDP reported in the national currency to be converted to some common basis. The simplest way is to use exchange rates. This approach has serious drawbacks, however, because many goods and services are not traded, and because of exchange controls and high-frequency exchange rate fluctuations. A generally preferred approach is to use purchasing-power parity values to make international comparisons, though the PPP approach also has problems. ${ }^{80}$ On the other hand for comparisons over time for a specific country, it is preferable to adjust output by the appropriate price deflator from the country's national accounts.

Growth of labour productivity in manufacturing is a useful supplement to the growth of economy-wide productivity for two reasons. First, manufacturing is an important sector in its own right. Second, because there are serious conceptual problems with the measurement of output outside the goods-producing sector, value added (output) data for manufacturing are more widely available and vastly superior to value-added data for the service-producing sector. ${ }^{81}$ These data are available from the UNIDO Industrial Statistics Database. Purchasing-power-parity levels of manufacturing productivity would be useful as well, but are available for relatively few countries outside the OECD.

${ }^{78}$ Economists' terminology for the total effect of these influences is "total factor productivity" or "multi-factor productivity."

${ }^{79}$ Many of these linkages are evident, for example, in the literature on job satisfaction. On the one hand, high job satisfaction has been shown to be a good predictor of desirable outcomes for the employer (e.g., low turnover). On the other hand, the strongest predictors of job satisfaction are usually attributes of decent work - pay, job security, safety, perceived fairness, etc. See discussion and references in Joseph A. Ritter and Richard Anker, Good Jobs and Bad Jobs: Workers' Evaluations of Their Jobs in Five Countries, manuscript, Statistical Development and Analysis Unit, ILO, 2002.

${ }^{80}$ For details see Robert Summers and Alan Heston, "The Penn World Table (Mark 5): An Expanded Set of International Comparisons", 1950-1988," Quarterly Journal of Economics, May 1991, vol. 106, number 2.

${ }^{81}$ The goods-producing sector also includes agriculture, mining and construction, but data are not as widely available for these sectors. 
The presence of high inflation, regardless of its cause, is a signal that implementation of policies to improve decent work is likely to face an uphill struggle. A country's inflation rate bears on decent work in several ways. First, because of contractual, legal and customary considerations, the monetary value of wages is often fixed for a specific or indefinite period. The consequence of these varying periods of rigidity is that inflation-a fundamentally macroeconomic phenomenon - can arbitrarily change a worker's wage relative to other workers and relative to the prices of food, housing, and other essentials. A similar problem affects self-employed workers. It may be difficult to adjust the prices of the goods or services they sell, even though the prices of inputs and consumer items are increasing. ${ }^{82}$

Another reason inflation has a bearing on decent work has to do with the root causes and social consequences of inflation. The inflation rate is often a kind of "canary in the coal mine" with respect to the political economy of a country, predicting when a government fiscal position is unsustainable. Beyond a certain point, if a national government chooses or is forced to pay for expenditures by issuing money (or monetizing its debt), the result will be inflation. It is an unfortunate fact of recent history that an unsustainable fiscal position is often resolved largely by reducing social protections.

The preferred measure for inflation rate is the consumer price index, which is used widely as a price deflator to obtain real prices, wages, and incomes. An alternative, a GDP-related price index (the traditional deflator or a chain-price index) offers broader coverage of the economy, but is often less timely. For international comparisons, only broad distinctions (among, for example, high, moderate, and low inflation countries) are reasonable and so, the difference between these two types of price indexes is of minor consequence. For this reason, available price deflators reported in ILO (and IMF) databases would be used regardless if they are consumer price deflators or a GDP price deflator.

\section{Education of the adult population}

Almost everywhere, education provides entrée to more desirable jobs. It also significantly affects labour productivity and therefore economic growth. Education is becoming increasingly important with each passing year and with the increasing pace of technological change. Among the skills and knowledge gained through formal education, the single most important one is the ability to read. Since reading is usually learned and schooling completed before labour market entry, educational attainment does not measure decent work per se, but is a critical part of the backdrop for decent work and the sustainability of progress towards decent work.

The indicators suggested here are the percentages of adult men and women who are literate and the percentages of men and women who have completed a secondary education. Both indicators are available for a large number of countries.

\footnotetext{
${ }^{82}$ There is no compelling evidence that these microeconomic distortions are serious when the inflation rate is low, but high inflation rates can result in significant redistribution of income and wealth. Indexation can reduce the severity of damage from inflation; Brazil's economy for example, is widely believed to be less susceptible to damage from inflation because of widespread indexation of prices and labour contracts.
} 


\section{Composition of employment by economic sector}

The observed prevalence of decent work in a country is determined in part by the structure of its economy. Certain industries are, by nature, safer, more likely to be unionised and provide higher than average compensation. The indicators selected to represent the broad outlines of a country's economic structure are the shares of employment in agriculture, industry, and services. For example: (1) workers in agriculture tend to work on family owned farms and have relatively low incomes; (2) industrial workers are often paid relatively well and are more likely to be union members; (3) labour statistics are likely to be most complete for the industrial sector.

\section{Income Inequality}

Decent work is intimately intertwined with income distribution and inequality. Decent work is unlikely to be viable where the distribution of economic rewards is grossly unequal, and great inequality can be taken as a sign of socio-political resistance to decent work. The distribution of economic rewards is unlikely to be grossly unequal where decent work prevails and decent work policies are believed to help reduce inequality. The details of the interplay between inequality and decent work in each country require attention to the specific situation of each country, but the broad outlines, both internationally and over time, can be captured in an index of inequality. Here we use the ratio of income or consumption of the top 10 percent (ranked by income or consumption) to the bottom 10 percent. ${ }^{83}$

\section{Poverty}

While decent work for all adults is a valid social objective in its own right, progress toward decent work also contributes to other social goals. In particular, decent work contributes to achieving the UN's Millennium Goal of eradicating extreme poverty and hunger. Noting this linkage is more than a restatement of the obvious connection between earnings and poverty. Beyond earnings, the absence of other aspects of decent work is likely to undermine poverty reduction strategies. For example, unsafe work increases the risk of injury and thus poverty for the entire household. Lack of social dialogue perpetuates poor work relationships. Discrimination and gender equity in the labour market directly increases the poverty rate among female-headed households. Other examples are not difficult to find. The indicators selected are the widely used percentages of the population who subsist on less than $\$ 1$ per day and less than $\$ 2$ per day.

\section{Informal economy employment}

A now almost traditional classification for employment is the formal/informal distinction. That the 2002 International Labour Conference took up the informal economy as one of its main agenda items is indicative of the visibility of, and concern about, the informal economy. ${ }^{84}$ This is not surprising, since informal economy employment is often associated with the absence of various characteristics of decent work such as low pay and absence of social protection. ${ }^{85}$ Given the importance laypersons and labour market

${ }^{83}$ The choice of income or consumption is based on data availability. See World Bank, World Development Indicators 2000.

84 See Decent work and informal economy. International Labour Conference $90^{\text {th }}$ Session Report IV. ILO, Geneva, 2002.

85 The ILO Employment Sector (2002a) report, Men and Women in the Informal Economy: A Statistical Picture prepared for the ILO Labour Conference introduced a new concept: informal 
specialists in developing countries attached to the informal economy, it makes sense to include employment in the informal economy as a decent work indicator. On the other hand, an informal economy indicator does not provide much value-added for measuring decent work in the sense that the characteristics of informal economy employment associated with not decent work should already be captured by the other suggested decent work indicators in this paper. It is for this reason that an indicator of employment in the informal economy is included in the Social and Economic Context section and not as an indicator of Employment Opportunities or Social Protection. This is also fully in line with the Conclusions Concerning Decent Work and the Informal Economy as stated in the Provisional Record No. 25 of the International Labour Conference discussions in 2002 which, inter alia, stipulates that the efforts for the Office should be to:

- develop greater understanding of the relationship between the informal economy and the feminisation of work, and identify and implement strategies to ensure that women have equal opportunities to enter and enjoy decent work;

- assist member States to collect, analyse and disseminate consistent, disaggregated statistics on the size, composition and contribution of the informal economy that will help enable identification of specific groups of workers and economic units and their problems in the informal economy and that will inform the formulation of appropriate policies and programmes. ${ }^{86}$

The $15^{\text {th }}$ International Conference of Labour Statisticians in 1993 adopted a resolution on employment in the informal economy. According to ILO (2002) prepared by the ILO Bureau of Statistics, this resolution defined employment in the informal economy as consisting of jobs in informal economy enterprises. The latter is defined on the basis of the following criteria: (i) enterprises are private and unincorporated, (ii) at least some of production is meant for sale or barter, (iii) enterprise size is below a threshold, (iv) enterprises are not registered under national legislation (e.g., social security laws, tax laws, commercial acts), and (v) for practical reasons, enterprises are engaged in non-agricultural activities. This is a complex set of criteria for defining the informal economy, and partly for this reason national definitions of the informal economy differ. For example, Latin American countries often use size of establishment (e.g., Panorama Laboral, 2001) ${ }^{87}$ and restrict their estimates to urban areas, while others use workers' registration with the social security system. Non-registration is commonly used in other parts of the world (see for example, ILO, 2002a). Restricting this indicator to urban non-agricultural employment makes sense from both practical and conceptual points of view. Family work on family farms is difficult to measure accurately, and national practices treat this work unevenly as regards inclusion in the informal economy.

Table 23 presents estimates of informal economy employment based on two definitions, a harmonised internationally comparable definition (drawn up by the so-called Delhi Group) and the official national definition. As expected, the informal economy is especially large in the low-income countries Ethiopia and India, with roughly half of total employment in each country. In comparison, only about 5 percent of total employment is in the informal economy in Russia. It is noteworthy how sensitive informal economy estimates are to the definition used. This is especially marked for rural areas. Thus while

employment. The main distinction between employment in the informal economy and informal employment is that the former is an enterprise based concept, while the latter is a job based concept. Both are concerned with employment that does not have social protections and benefits.

${ }^{86}$ Provisional Record No. 25, International Labour Conference $90^{\text {th }}$ session, ILO, Geneva, 2002, pp. $25 / 61$.

${ }^{87}$ ILO Panorama Laboral, Latin America and the Caribbean, ILO, Lima, 2001. 
according to Ethiopia's official national definition, 74 percent of workers (and 87 percent of rural workers) are in the informal economy, "only" 50 percent of total workers as well as rural and urban workers are estimated to be in the informal economy based on the Delhi Group definition. Russia has a similarly large discrepancy for rural areas. These data show that official national estimates for urban areas as compared to rural areas tend to be closer to the internationally harmonised definition. Thus while these data make it quite clear that considerable work is required to improve the international comparability of informal economy data, they also imply that this should be easier for urban areas. A good start in this direction has been made by ILO (2002), which provides detailed documentation of the definitions used for official national estimates, as well as by ILO $(2002 \mathrm{a})^{88}$ that produces a set of national estimates. It should be possible to build on these efforts to produce reasonable comparable data for a sizable number of developing countries.

${ }^{88}$ ILO, Compendium of official statistics on employment in the informal sector, STAT Working Paper - 2002 No. 1 . 
Table 23: Informal economy employment as percent of employment, rural and urban

\begin{tabular}{lcc}
\hline Country & \multicolumn{2}{c}{ Percent of employment } \\
\cline { 2 - 3 } & Harmonised definition of Delhi group & Official national definition \\
\hline Ethiopia a & 50.2 & 74.2 \\
Total & 50.7 & 86.9 \\
Rural & 49.2 & 50.6 \\
Urban & & \\
India ${ }^{\text {b }}$ & 45.8 & 55.7 \\
Total & 55.0 & 61.0 \\
Rural & 38.1 & 51.3 \\
Urban & & \\
Russia ${ }^{\text {a }}$ & 4.3 & 12.6 \\
Total & 3.7 & 23.8 \\
Rural & 4.5 & 9.2 \\
Urban & & \\
& & \\
Notes: ${ }^{1}$ 1999 b 2000. & & \\
Source: LO, Compendium of official statistics on employment in the informal sector, STAT Working Paper, 2002, No. 1 ILO, 2002 \\
\hline
\end{tabular}

\section{Conclusions and recommendations}

This paper has been concerned with the measurement of decent work using statistical indicators. Its objective is to help enable the ILO and member States to measure decent work and monitor progress toward the elimination of decent work deficits. There is little doubt of the need for decent work indicators. In their absence, countries, workers, unions, employers and the general public are not in a position to know how they are doing compared to other countries, or to monitor progress toward reducing decent work deficits. The absence of decent work indicators also greatly reduces the ILO's ability to communicate its messages and affect public debates on labour and social issues.

In the absence of an agreed list of indicators, the considerable ongoing statistical efforts in the ILO such as in STAT, IFP/SES, KILM and the Latin American region are likely to remain ad hoc, overlapping and unevenly distributed across the different aspects of decent work. This would mean that the comprehensive nature of decent work would be lost, and this would undermine the very nature of the concept. Acceptance of a core set of decent work indicators would also have other major advantages. It would make it much easier for ILO to work together with constituents to ensure that there is national ownership of the decent work agenda and enable member states to compare their situation with other countries. Finally, a core set of internationally comparable indicators would allow ILO to make world and regional decent work estimates.

The paper began with the ILO Director General's brief description of decent work, and his proposition that decent work must be a central objective and engine of social and economic development. The paper carefully considers this description and a number of principles for the construction of indicators. Some key principles are: (1) The word "decent" connotes particular concern for the most vulnerable, implying a concern with adequacy and therefore distributions rather than averages. (2) Indicators should be 
sensitive to the fact that, with the exception of fundamental rights, decency must be interpreted relative to the norms of society. (3) Decent work is concerned with the actual situation people face, so indicators should focus on outcomes. (4) Decent work is a comprehensive framework, therefore it is necessary to have indicators for the full range of decent work concerns.

The paper then translates the Director General's description into ten characteristics of decent work that ordinary people would understand and apply to their own jobs, and commences the task of identifying possible indicators. For practical reasons, such as limited financial and human resources in countries and the ILO, it was clear that a final list of decent work indicators to measure these eleven aspects of work will need to be parsimonious. To this end, we required that indicator candidates meet four main criteria: (i) conceptual relevance, (ii) easily communicated interpretation, (iii) availability of data for a range of countries (industrialized, developing, and transition), and (iv) a reasonable level of international comparability. Our belief is that realism and feasibility are as important as conceptual relevance, and that rejecting possible indicators is as important as suggesting indicators.

Based on the principles and concepts noted in earlier sections of the paper, section 4 provides detailed discussions for each of the ten basic characteristics of decent work, including suggestions of specific indicators. Discussions of section 4 are concrete, based in part on illustrative national data. The intention is to critically appraise conceptual issues, current knowledge and data gaps. These discussions resulted in a suggested core set of decent work indicators, along with suggestions for additional indicators that merit consideration for further development in the future. Section 4 also discusses a small number of indicators to measure the economic and social context of decent work.

Table 24 collates the suggestions and discussions of decent work indicators in this paper. Suggested indicators are listed in column 1. Column 2 notes when indicators should be reported separately for men and women, so that a full picture of gender inequalities can be ascertained. Column 3 summarises implementation issues that need to be addressed in the measurement of the suggested indicators. Column 4 calls attention to major shortcomings, omissions and other possibilities in each area.

The process described above leads to four broad recommendations. The first is the most directly related to the work of this paper. The second and third address how this effort fits into the larger effort of making decent work the guiding principle of the ILO. 


\section{Recommendation 1: Undertake a process to establish and measure ILO core decent work indicators.}

Implementation of this recommendation will require several steps:

Establish a list of ILO core decent work indicators. Based on constructive comments and discussions of the present paper, the Office should move quickly to settle on a core set of ILO decent work indicators for immediate measurement.

Measure the ILO core decent work indicators. The feasibility and usefulness of the agreed indicators should be further explored during the next year by measuring them for as many countries as possible. To ensure that likely difficulties are confronted and addressed, countries from all regions and development levels should be included, and efforts should be made to improve cross-country comparability.

The outcome of this work over the next year should be a series of publications that provide results, methodological advice, and recommendations. Synthesising experience and results, the Office should then work toward a more permanent set of ILO core decent work indicators.

A total of 30 indicators are suggested to measure decent work in this paper (see Table 24). This represents, in our opinion, a feasible set of indicators that could be measured in the near future. It is, at the same time, a challenging list, as would be any list, in light of the comprehensive nature of decent work and the relative neglect in labour statistics of decent work aspects outside of the employment-wages-hours nexus. For example, data collection systems would need to be set up in areas where there are major data gaps, such as social dialogue, social protection, and safe work. Discussions with the technical units on how to do this are underway.

The initial stage of measuring the decent work indicators listed in column 1 in Table 24 over the next year will require an Office-wide effort. The Policy Integration Department (SDA and STAT) should play a major role in this effort, providing leadership, coordination and technical support. Much of the work will need to be done by technical sectors and field offices, since they have the specialised technical expertise and on the ground experience. Since the ultimate objective is to establish a sustainable system for the collection and reporting of decent work indicators, technical sectors and the field will need to build this into their longer term programmes.

\section{Recommendation 2: Encourage regions and countries to measure decent work.}

The Office should encourage and support efforts by regions and countries to improve and extend the indicators where data availability and special regional or national concerns make this possible and desirable. However, in the long-term interest of having a worldwide set of indicators, these efforts should augment, rather than supplant, the core indicators. Within the ILO, such efforts should use the shared framework, agreed upon as part of the organization-wide discussions recommended above.

Some regions are more advanced as regards decent work indicators. In the Latin American region, various efforts to develop indicators have been underway for some time. INTEGRATION/SDA has undertaken a collaboration with the European Foundation to study decent work issues in the European Union and accession countries. These efforts should be built on and emulated by other regions. At the national level, ILO should sponsor in-depth statistical profiles of decent work reports in countries to develop and demonstrate the usefulness of decent work indicators. These reports are also be an important aspect of Recommendation 1 in that they would highlight difficulties and 
problems with the proposed core indicators and, ideally, decide on approaches to measuring decent work for each of the eleven aspects of decent work identifies in this paper. Such efforts are a natural extension of the ILO decent work country pilot projects and a necessary step to decent work becoming an integral part of national policy analysis and advise.

\section{Recommendation 3: Integrate the indicators into ILO's ongoing work.}

There is little point in developing decent work indicators if they are not going to be used in policy analysis and advice. Nor is a list of ILO core decent work indicators likely to evolve in a useful direction if they are not used in this way. This should involve going beyond simply describing decent work, to also improving our understanding of how different aspects of decent work interrelate, how development affects decent work, and how decent work affects poverty and economic growth. Strategies should be developed for using ILO decent work indicators in research, policy analysis, policy advice and communication with constituents and the public. These efforts will be especially useful in helping to set priorities and realistic goals.

\section{Recommendation 4: Develop a strategy to address aspects of decent work that cannot be adequately measured at present.}

It needs to be acknowledged that, regardless of ILO's near-term efforts, data will not be available to measure some major aspects of decent work in most developing countries. These areas include safe work, balancing work and family life, stability and security of work, fair treatment (apart from gender issues), some social protection contingencies, unacceptable work, and several aspects of social dialogue. Rectifying this situation will require new and better data collection, which will take time and resources.

To address the reality that labour data for important aspects of decent work for developing countries will remain weak for the near future, ILO should invest in the development of survey instruments for individuals and establishments so that decent work in its broader sense can be measured better. Appropriate decent work survey questions should be developed, tested and calibrated over the next several years by building on current efforts and experiences in the world and in the Office, such as those mentioned in this paper by IFP/SES, STAT, IPEC, and CONDIT. The goal should be to develop the tools needed for countries, especially developing countries, to measure decent work as a standard part of their national statistical programmes. In this way, recommendations 2 , and 3 and 4 would ultimately move toward a single goal: decent measurement of decent work everywhere.

One important area which is not well addressed in this paper is legal and regulatory frameworks at the national and international levels. This includes ratifications of ILO conventions, especially the seven core conventions and relevant national laws that affect the extent to which work is decent. A complementary and integrated set of indicators on laws and regulations for each of the major aspects of decent work (e.g., unemployment insurance, protection from dismissal, ILO core conventions, restrictions on the right to strike, restrictions on the right to organise, statutory minimum wage, etc.) would be worth developing through systematic coding of this information. Such an effort would need to include information that also measures effective coverage and scope so that they reflect the actual situation for workers. 


\section{Closing Remarks}

This paper has suggested a list of ILO decent work indicators and a process to implement it. Thus, it has provided the basis for the development and measurement of an ILO core set of decent work indicators. Clearly the suggested indicators are not perfect, nor are they likely to meet the detailed needs of technical programmes or specific countries or regions of the world. They are by design intended to be a feasible, minimal set of indicators that are relevant around the world and at the same time reflect the comprehensive nature of the decent work concept. It would not be possible to capture and measure in a parsimonious list all aspects of decent work in detail, and it is for this reason that this paper has devoted considerable space to exploring the feasibility and difficulties of different possible indicators, both those that can be measured soon for a substantial number of countries as well as those requiring additional conceptual and measurement development.

Following through to establish and measure ILO core decent work indictors will not be easy, but it is possible. It will require the entire ILO working together in collaboration with constituents and national statistical agencies. It is an important endeavour, because the credibility and legitimacy of the decent work agenda depend in no small degree on its success.

This paper should be seen as a necessary first step to establishment and measurement of a core set of ILO decent work indicators. It provides a suggested list of ILO decent work indicators, not a final list. Our expectation is that through dialogue and interest in a common good it will be possible to move forward with the measurement of decent work using statistical indicators. 
Table 24. Summary of suggested decent work indicators

(Blue/italics indicate cross-reference to indicator presented in another section.)

Indicators

By

Sex? Implementation issues

Shortcomings, omissions, possibilities*

\section{Employment Opportunities}

\begin{tabular}{|lcl|}
\hline 1. Labour force participation rate & $\boldsymbol{?}$ & $\bullet$ Improve comparability. \\
\hline 2. Employment-population ratio & $\boldsymbol{?}$ & $\bullet$ Improve comparability. \\
\hline 3. Unemployment rate & $\boldsymbol{?}$ & $\bullet$ Improve comparability. \\
\hline 4. Youth unemployment rate & $\boldsymbol{?}$ & $\bullet$ Improve comparability. \\
\hline Time-related underemployment rate & $?$ & $\bullet$ See entry under Decent Hours \\
\hline 5. Share of wage employment in non-agricultural employment & $\boldsymbol{?}$ & $\bullet$ Improve comparability. \\
\hline
\end{tabular}

Ongoing efforts to improve international comparabiltiy should be incorporated into the indicators as improvements become available.

\section{Unacceptable Work}

6. Children not in school by employment status (percent by age)

7. Children in wage employment or self-employment (percent by age)
? $\quad$ Need to establish when factors other than work cause non-attendance such as absence or poor quality of local school.

? $\quad$ Limited data availability.**

\section{Adequate Earnings and Productive Work}

8. Inadequate pay rate (percent of employed below $1 / 2$ of median hourly earnings or absolute minimum, whichever is greater, by status in employment)

9. Average earnings in selected occupations October Inquiry.

- Improve comparability, country coverage and consistency of October Inquiry data.

Excessive hours of work

- See entry under Decent Hours

Time-related underemployment rate

10. Employees with recent job training (percent with job training during last 12 months provided or paid for by employer or state)
? $\quad$ Requires earnings distribution, not averages. - Improve comparability of earnings data.

- Choice of relative and absolute thresholds requires further consideration.
- Neglected aspects for future development: forced labour,

hazardous and other worst forms of child labour.

- Total "work" time, including non-economic household work may be relevant.

- Regular attendance and progress in school also important to consider.
- Earnings often poorly measured for self-employed workers, therefore useful to report indicator by status in employment. - Key neglected aspect: irregularity of employment/earnings. - Superficial portrayal of training. 
11. Excessive hours of work (percent of employed, by status in employment)

12. Time-related underemployment rate (percent of employed persons working less than hours threshold, but available and wanting to work additional hours)
? $\quad$ Comparability issues include usual hours vs. reference period hours, main job hours vs. hours on all jobs.

? $\quad$ Limited data availability.**

- Improve comparability.
- Neglected aspects: atypical/asocial hours, reasons for

excess hours, commuting time.

\section{Stability and Security of Work}

13. Tenure less than one year (percent of employed persons who have held their main job/work for less than one year, by age)

? Limited data availability.**

? $\quad$ Limited data availability.**

- Comparability problems surround use of the word "temporary" in survey questions.
- Indicators primarily backward-looking; neglect perceptions of future security.

- Key neglected aspect: irregularity (intermittency) of employment. jobs as temporary)

\section{Balancing Work and Family Life}

15. Employment rate for women with children under compulsory school age (ratio to employment rate for all women aged 20-49)

Excessive hours of work
? $\quad$ Will require special tabulations from labour force survey for some countries.

- See entry under Decent Hours
- Neglected aspects: maternity and paternity job protection and monetary benefits, flexible hours, atypical/asocial hours, child care, leave for care of sick or injured relatives.

\section{Fair Treatment in Employment}

16. Occupational segregation by sex (percent of non-agricultural employment in male- or female-dominated occupations and index of dissimilarity)

\section{Female share of employment in managerial and} administrative occupations (ratio to female share of nonagricultural employment)
? Comparability problems around level of detail of occupational classification.

? $\quad$ Comparability problems stemming from differences between ISCO-68 and ISCO-88 classifications.
- Other bases for discrimination (ethnic, religious, migran status, etc.) not considered.

- Neglected aspects: sexual harassment, workplace abuse and violence, employer/employee relations (handling of grievances, etc.), autonomy.
? $\quad$ See entry under Employment Opportunities

? See entry under Adequate Earnings - See entries under other headings 


\section{Safe Work}

18. Fatal injury rate (per 100,000 employees)

19. Labour inspection (inspectors per 100,000 employees and per 100,000 covered employees).

Excessive hours of work

20. Occupational injury insurance coverage (percent of employees covered by insurance)

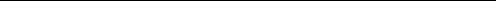

? Improve comparability

- Set up data collection system.

- Estimating covered employment may prove difficult.

- See entry under Decent Hours

? $\quad$ Set up data collection system.
- Nonfatal injuries not covered due to overwhelming

comparability, coverage, and enforcement problems in reporting systems.

- Fatal injury rate and labour inspectors cover only formal sector.

- Fatal injury data are often of poor quality.

- Neglected aspects: sick leave entitlement, physical and mental health problems other than injuries, entitlement to breaks, toilet facilities etc.

- No coverage of risk except long hours, but accurate measurement of a comprehensive set of risks would be very difficult.

- Labour inspectors' effectiveness varies.

\section{Social Protection}

21. Public social security expenditure (percent of GDP, separately for total, health services, and old-age pensions).

22. Public expenditure on needs-based cash income support (percent of GDP).

23. Beneficiaries of cash income support (percent of poor)

24. Share of population over 65 benefiting from a pension

25. Share of economically active population contributing to a pension fund.

26. Average monthly pension (percent of median/minimum earnings).

Occupational injury insurance coverage
- Available data not timely for some countries.

- Conceptual development required for consistency .

- Set up data collection system.

- Set up data collection scheme.
$?$

- See entry under Safe Work
- Neglected aspects: share of population covered by health care services, sickness insurance, private sector expenditures and coverage, distributional aspects of pension and health benefits, maternity/paternity protections.

- Data for gender differentials on pension indicators may not be widely available. 


\begin{tabular}{ll}
\hline 27. Union density rate & $\bullet$ Set up data collection system. \\
\hline 28. Collective wage bargaining coverage rate & $\bullet$ Set up data collection system. \\
\hline 29. Strikes and lockouts (per 1000 employees) & $\bullet$ Improve comparability. \\
\hline
\end{tabular}

- Not covered and for future development: statistical indicators and collective bargaining for effective right of freedom of association.

- Neglected aspects: union democracy, quality of social dialogue, participation in workplace decisions, quality of employer/employee relations, gender differentials for union membership.

\section{Socio-Economic Context}

\begin{tabular}{|c|c|c|}
\hline Output per employed person (PPP level) & & \\
\hline Growth of output per employed person & & \\
\hline Inflation (consumer prices where available) & & \\
\hline $\begin{array}{l}\text { Education of adult population (adult literacy rate, adult } \\
\text { secondary school graduation rate) }\end{array}$ & $?$ & $\begin{array}{l}\text { Data are available for most countries for all } \\
\text { indicators from ILO or other international }\end{array}$ \\
\hline $\begin{array}{l}\text { Composition of employment by economic sector (agriculture, } \\
\text { industry, services) }\end{array}$ & $?$ & $\begin{array}{l}\text { organisations, except informal economy } \\
\text { employment. }\end{array}$ \\
\hline $\begin{array}{l}\text { 30. Informal economy employment (percent of non-agricultural } \\
\text { or urban employment) }\end{array}$ & ? & \\
\hline $\begin{array}{l}\text { Income inequality (ratio of top } 10 \% \text { to bottom } 10 \% \text {, income or } \\
\text { consumption) }\end{array}$ & & \\
\hline $\begin{array}{l}\text { Poverty (percent of population subsisting on less than } \$ 1 / \text { day } \\
\text { and less than } \$ 2 / \text { day) }\end{array}$ & & \\
\hline
\end{tabular}
$\underline{\text { Notes }}$

* Some "neglected aspects" could be measured using available methodology, but data are not collected for a sufficiently wide range of countries at present

** Limited data availability implies that data are not presently available for a substantial number of developing countries. 